\title{
Neuropsychiatric Disturbances in Alzheimer's Disease: What Have We Learned from Neuropathological Studies?
}

\author{
Debby Van Dam ${ }^{1,2}$, Yannick Vermeiren ${ }^{1,2}$, Alain D. Dekker ${ }^{1,2}$, Petrus J.W. Naudé ${ }^{1,2}$ and \\ Peter P. De Deyn ${ }^{1,2,3, *}$
}

${ }^{1}$ Laboratory of Neurochemistry and Behaviour, Institute Born-Bunge, Department of Biomedical Sciences, University of Antwerp, Wilrijk, Belgium; ${ }^{2}$ Department of Neurology and Alzheimer Research Center, University of Groningen, University Medical Center Groningen, Groningen, The Netherlands; ${ }^{3}$ Department of Neurology and Memory Clinic, Hospital Network Antwerp (ZNA) Middelheim and Hoge Beuken, Antwerp Belgium

\section{A R T I C L E H I S T O R Y \\ Received: January 18,2016 \\ Accepted: April 27,2016 \\ DOI: $10.2174 / 1567205013666160502$ 123607}

\begin{abstract}
Neuropsychiatric symptoms (NPS) are an integral part of the dementia syndrome and were therefore recently included in the core diagnostic criteria of dementia. The near universal prevalence of NPS in Alzheimer's disease (AD), combined with their disabling effects on patients and caregivers, is contrasted by the fact that few effective and safe treatments exist, which is in part to be attributed to our incomplete understanding of the neurobiology of NPS. In this review, we describe the pathological alterations typical for $\mathrm{AD}$, including spreading and evolution of burden, effect on the molecular and cellular integrity, functional consequences and atrophy of NPS-relevant brain regions and circuits in correlation with specific NPS assessments. It is thereby clearly established that NPS are fundamental expressions of the underly-

Peter P. De Deyn ing neurodegenerative brain disease and not simply reflect the patients' secondary response to their illness. Neuropathological studies, moreover, include a majority of end-stage patient samples, which may not correctly represent the pathophysiological environment responsible for particular NPS that may already be present in an early stage, or even prior to AD diagnosis. The burdensome nature and high prevalence of NPS, in combination with the absence of effective and safe pharmacotherapies, provide a strong incentive to continue neuropathological and neurochemical, as well as imaging and other relevant approaches to further improve our apprehension of the neurobiology of NPS.
\end{abstract}

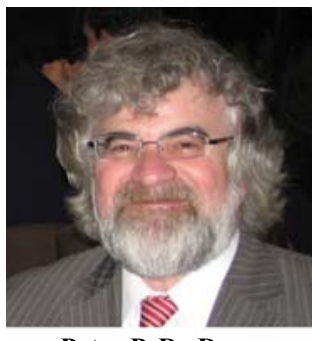

Keywords: Aggression, amyloid, depression, neurofibrillary tangles, neuronal loss, psychosis, neurotransmitter.

\section{INTRODUCTION}

As the prototype of cortical dementias, Alzheimer's disease (AD) presents with prominent cognitive deficits in several domains, including episodic and semantic memory, executive and attentional processing, as well as visuospatial functioning [1], which have been intensely studied for many decades. In addition to the declining cognitive function, AD and related dementias are equally associated with a high prevalence of behavioral and psychiatric disturbances [2], consisting of depression, apathy, agitation, aggression, sleep disorders, delusions and hallucinations (psychosis), activity disturbances, anxieties/phobias, irritability, disinhibition and euphoria/dysphoria [3-7]. Originally labelled as behavioral and psychological signs and symptoms of dementia (BPSD) [8], these symptoms have more recently also been clustered under the umbrella term of neuropsychiatric symptoms (NPS) [7].

\footnotetext{
*Address correspondence to this author at the Laboratory of Neurochemistry and Behaviour, Institute Born-Bunge, Department of Biomedical Sciences, Faculty of Pharmaceutical, Biomedical and Veterinary Sciences, and, Faculty of Medical and Health Care Sciences, University of Antwerp, Universiteitsplein 1, BE-2610 Wilrijk (Antwerp), Belgium; Tel: +32 32652620; Fax: +32 32652618;

E-mails: peter.dedeyn@uantwerpen.be,dedeyn@skynet.be
}

NPS are an integral part of the dementia syndrome and affect the majority of all dementia subjects over the course of their illness [9]. NPS have an important impact on patients, caregivers/relatives, and society at large. They impact patients' functioning and often cause premature transition to structured living environments and institutionalization [10]. Since they are often more difficult to cope with than cognitive changes, they imply a major burden to family members and health care professionals [11]. Moreover, NPS have been linked to accelerated cognitive decline [12], increased risk of secondary morbidity or injury [13], as well as greater risk of mortality [10]. Altogether, NPS are a major cause of diminished quality of life for both patients and caregivers and contribute significantly to the overall costs of dementia care [14].
Despite being almost universally present during the course of dementia, only in the recently published fifth edition of the Diagnostic and Statistical Manual of Mental Disorders (DSM), NPS have finally been recognized as an integral part of the disease process, and, moreover, have been included in the core diagnostic criteria of dementia, referred to as 'major or mild neurocognitive disorder (NCD)' [15]. DSM-V criteria circumscribe NPS as 'specifiers', i.e. psy- 
chotic features, mood disturbances (depression, anxiety, and elation), agitation, apathy, disinhibition, sleep disturbances, hyperphagia and hoarding. Furthermore, in the additional description of 'major or mild NCD due to Alzheimer's disease', depression and apathy in the earliest stages of $\mathrm{AD}$, together with psychotic features, irritability, agitation, combativeness, and wandering in the advanced stages of the disease, are all classified as 'associated features supporting the diagnosis' [15], thereby at last rightly acknowledging the importance of NPS in dementia diagnosis.

Given that up to $80-97 \%$ of AD patients in the general population may suffer from NPS at some point during their disease course [16], this near universal prevalence of NPS in $\mathrm{AD}$, combined with their serious and disabling effects on patients and caregivers, has recently focused significant attention on the fact that few effective and safe treatments exist, which can - at least partially - be attributed to our incomplete comprehension of the neurobiology of NPS. This paper will describe the pathological alterations typical for $\mathrm{AD}$, including spreading and evolution of burden, effect on the molecular and cellular integrity, functional consequences and atrophy of NPS-relevant brain regions and related circuits. Although the main focus will be on human studies, also a few relevant animal model approaches will be discussed. The development and phenotyping of animal models is indeed essential in AD-related research as valid models enable the appraisal of early pathological processes - which are often not or poorly accessible in patients $[17,18]$.

\section{NEUROPATHOLOGICAL FEATURES OF AD}

The neuropathological hallmarks of AD include "positive" lesions such as amyloid plaques, cerebral amyloid angiopathy, neurofibrillary tangles, and neuroinflammatory responses, and "negative" lesions, such as neuronal and synaptic dysfunction and loss.

\subsection{Amyloid-Related Pathology}

One of the major positive hallmarks of both familial and late-onset $\mathrm{AD}$ is the extracellular accumulation of amyloid- $\beta$ $(\mathrm{A} \beta)$ peptides in amyloid or senile plaques (SP). A $\beta$ is a 3643 amino acid fragment of the transmembrane and extracellular domains of the amyloid precursor protein (APP) [19]. The APP amyloidogenic pathway is responsible for producing $A \beta$, and involves the cleavage of APP by $\beta$-secretase, followed by $\gamma$-secretase. The non-amyloidogenic pathway, in which APP is first cleaved by $\alpha$-secretase, results in a neuroprotective sAPP $\alpha$ fragment. Although the excessive aggregation and deposition of $\mathrm{A} \beta$ has been reported to cause neurodegeneration in $\mathrm{AD}$, the amyloidogenic pathway is a physiological process important for normal neuronal functioning [20], especially as modulator of synaptic plasticity in its monomeric form [21]. A $\beta$ is characterized by the intrinsic tendency to form aggregates that are referred to as oligomers, protofibrils or mature amyloid fibrils, depending on their appearance in electron and atomic force microscopy $[22,23] . A \beta 1-40$ and $A \beta 1-42$ are the most common types with the more hydrophobic $A \beta 1-42$ being particularly prone to aggregation $[24,25]$. Although typically $A \beta$ plaques are classified into diffuse, dense-core and neuritic plaques, based on their morphology and positive or negative staining with
Thioflavin-S or Congo Red, they exist as a continuum in which complex mixtures of fibrillar, granular, and even soluble $A \beta$ forms are associated with highly varying degrees of surrounding glial and neuritic alterations [26, 27].

Although some have reported that the insoluble form of $\mathrm{A} \beta$ is the major variant causing $\mathrm{AD}$ pathology [28], others state that both insoluble and soluble forms are observed in symptomatic $\mathrm{AD}$ patients, as well as in presymptomatic cases [29]. In this respect, several lines of investigation now support the view that increased levels of soluble $A \beta 1-42$ oligomers might lead to synaptic damage, neurodegeneration, and, accompanying memory loss, mainly by inhibiting long-term potentiation, damaging spines and interfering with activity-regulated cytoskeleton associated protein distribution $[26,30]$.

Familial forms of AD can be caused by mutations in $A P P$ on chromosome 21 [31]. The greater part of these mutations are located at the secretase cleavage sites, or the transmembrane domain of APP. Mutations near the $\beta$ - and $\gamma$-secretase cleavage sites have been reported to lead to an overproduction of total $A \beta$, or an increased $A \beta 1-42 / A \beta 1-40$ ratio. Furthermore, mutations within $A \beta$ are hypothesized to increase its tendency to form aggregates [32, 33]. Since presenilin (PSEN)-1 and PSEN2 proteins constitute the active site of $\gamma$ secretase [34], mutations in their coding genes (PSEN1 and PSEN2) result in a deficient $\gamma$-secretase and can also lead to AD pathology [35]. In fact, most familial AD cases are attributed to mutations in PSEN1 or PSEN2 [34]. Of interest to note here is Down syndrome (DS) considered a human overexpression model of AD based on trisomy of chromosome 21 which harbors the $A P P$ gene [36]. In addition to the congenital intellectual disability, DS is associated with accelerated ageing, including a significantly increased risk of developing early-onset AD; approximately $50-70 \%$ of DS individuals develop AD by the age of $60-70$ years $[37,38]$. Trisomy of $A P P$ is likely to make a significant contribution to the increased frequency of dementia in people with DS, although other genes than APP located on chromosome 21 may also contribute to the early onset of AD in DS [39].

Regarding sporadic AD, the apolipoprotein E (APOE) $\varepsilon 4$ allele is believed to account for most of the genetic risk, but as a susceptibility gene it is neither necessary nor sufficient to cause late-onset AD [40]. APOE is a cholesterol transporter in the brain, and is essential for deposition and fibrillization of $A \beta$ and plaque formation [41].

\subsubsection{Amyloid Cascade Hypothesis}

It is widely assumed that the neuropathology of $\mathrm{AD}$ is initiated by abnormal aggregation and deposition of $\mathrm{A} \beta$ peptide, either due to increased $A \beta$ production or decreased $A \beta$ clearance. The aggregation and deposition of $\mathrm{A} \beta$ are hypothesized to subsequently cause neuronal damage and dementia. This theory is generally known as the amyloid cascade hypothesis, and is supported by several lines of evidence $[35,42]$. Firstly, the discovery that presenilin 1 and 2 (PSEN1 and PSEN2) enhance the processing of APP to amyloidogenic $A \beta$, through a direct effect on $\gamma$-secretase, is a first indication [43, 44]. Secondly, mutations in the gene encoding tau protein cause frontotemporal lobar degeneration with parkinsonism [45]. This dementia subtype is char- 
acterized by a severe deposition of abnormal tau in the brain, while no $A \beta$ inclusions can be found. This indicates that severe alterations in tau metabolism are not able to induce amyloid pathology. Therefore, it was considered that neurofibrillary tangles (NFTs, see 2.2) in AD only appeared after the occurrence of amyloid pathology, rather than before [35]. A third indication supporting the amyloid cascade hypothesis is that transgenic mice overexpressing mutant human APP and human tau, show increased NFT formation compared to mice overexpressing tau alone. Moreover, the number and structure of SP remained unaltered [46], suggesting that modified APP processing occurs before the appearance of NFT [35]. Fourthly, overexpression of chromosome 21-located genes in DS is associated with an increased risk of developing $\mathrm{AD}$, neuropathologically associated with extensive deposition of $\mathrm{A} \beta$ plaques, as well as neuroinflammation and substantial NFTs (Wisniewski et al., 1985), whereas other types of dementia, for example frontotemporal or Parkinson's disease dementia are not observed within this population [47].

However, observations by other research groups do not comply easily with the amyloid cascade hypothesis. It has been reported, for instance, that amyloid burden does not correlate with the severity and duration of the dementia syndrome, whereas several other clinicopathological studies confirmed that the amount and distribution of NFT indeed correlated with the severity and duration of the disease [26, 48]. The amyloid hypothesis therefore remains a debatable theory until present $[35,49]$. Moreover, despite plaque pathology being present in virtually all DS individuals aged $>40$ years [50] and increased A $\beta$ expression, 30-50\% of DS subjects will never develop clinical AD [51], implying indeed that the amyloid cascade theory may not fully cover AD etiology.

\subsubsection{Topographic Distribution of Amyloid Pathology}

As illustrated by (Fig. 1A), amyloid plaques mainly accumulate in the neocortex, but with a poorer predictability as opposed to NFT spreading. Amyloid deposits involve all six layers of the neocortex, even though layers I and VI are less affected than layers II-V [53]. In advanced AD cases, lesions can even be detected in the transitional area of cortical layer VI with the adjacent white matter. In general, two overall staging systems have been proposed. Firstly, Braak and Braak [54] distinguished three stages: stage A, with amyloid deposits preferentially in the basal portions of frontal, temporal and occipital lobes; stage $\mathrm{B}$, in which all neocortical association areas are affected, except for the primary sensory, motor and visual cortices, and with only mild lesions in the hippocampus; and stage $\mathrm{C}$, characterized by additional plaque formation in these primary neocortical areas, and sometimes amyloid deposits in the molecular layer of the cerebellum and several subcortical nuclei, such as striatum and thalamus among others. Secondly, Thal et al. [55] proposed five stages: stage 1 or the neocortical stage; stage 2 , with additional depositions in the entorhinal cortex, hippocampal formation, amygdala, and, insular and cingulated cortices; stage 3, with extra lesions in subcortical nuclei, such as basal forebrain cholinergic nuclei, thalamus, and, even white matter; stage 4, characterized by involvement of brainstem structures, such as substantia nigra and colliculi; and, finally, stage 5, where amyloid deposits are localized in the pons (raphe nuclei and locus coeruleus e.g.) and molecular layer of the cerebellum as well.

Recently, $A \beta$ deposit staging as measured according to the phases of deposition described by Thal et al. [55] have been implemented by Montine et al. [56] into an overall "ABC scoring" approach, which includes A $\beta$ plaque scoring (A score), as well as Braak NFT staging (B score; see section 2.2 Tau-related pathology) and neuritic plaque scoring (C score). The five stages of $A \beta$ plaque scoring [55] have been translated into the A score as follows: A score $0=$ stage $0 ; \mathrm{A}$ score $1=$ stage 1 or 2 ; A score $2=$ stage 3 ; A score $3=$ stage 4 or 5 .

\subsection{Tau-Related Pathology}

NFT consist of abnormally paired fibrils that are wound around each other, also referred to as paired helical fragments. The major component of NFT is hyperphosphorylated microtubule-associated protein tau (MAPT), although other proteins, such as ubiquitin [57, 58] and cholinesterases [59] might also be present. MAPT is an axonal protein binding to microtubules, hereby promoting microtubule assembly and stability [34]. Tau hyperphosphorylation in AD is initiated intracellularly and causes sequestration of tau and other microtubule-associated proteins. This, in turn, results in impaired axonal transport by disassembly of the microtubules, and impaired neuronal and synaptic function [60]. Moreover, aggregation of hyperphosphorylated tau into fibrils further hampers neuronal functioning. The distribution and extent of NFT in the brain of AD patients is associated with the severity and duration of the disease [48], suggesting that these lesions have a direct impact on neuronal functioning [58]. In the early stages, NFT are observed in the transentorhinal cortex, while in following stages, NFT further spread to the amygdala and hippocampus. As the disease progresses, NFT can also be found in neocortical association areas [61].

Three morphological stages have been defined: (1) preor diffuse NFT within the cytoplasm with well-preserved dendrites and a centered nucleus; (2) mature or fibrillary intraneuronal NFT consisting of cytoplasmatic filamentous tau aggregates causing displacement of the nucleus towards the periphery of the soma and distorted dendritic segments (neuropil threads); and (3) extraneuronal 'ghost' NFTs as a result of death of tangle-bearing neurons [26, 62].

The combination of the intracellular location of tau aggregates with the diverse ultrastructural conformations, based on the (combination of) different isoforms and various possible posttranslational modifications, as well as colocalization with other $\beta$-sheet structured protein deposits, complicates the development of ligands for tau imaging. Nevertheless, several selective tau radiotracers have been developed, but still lack the more widespread clinical application of Pittsburgh compound-B [63, 64].

\subsubsection{Topographic Distribution}

NFT accumulation starts in the allocortex of the medial temporal lobe (i.e. entorhinal cortex and hippocampus) and spreads to the associative isocortex, relatively sparing the primary sensory, motor, and visual areas (Fig. 1B). In total, Braak and Braak [55] distinguished six stages (I-VI). 

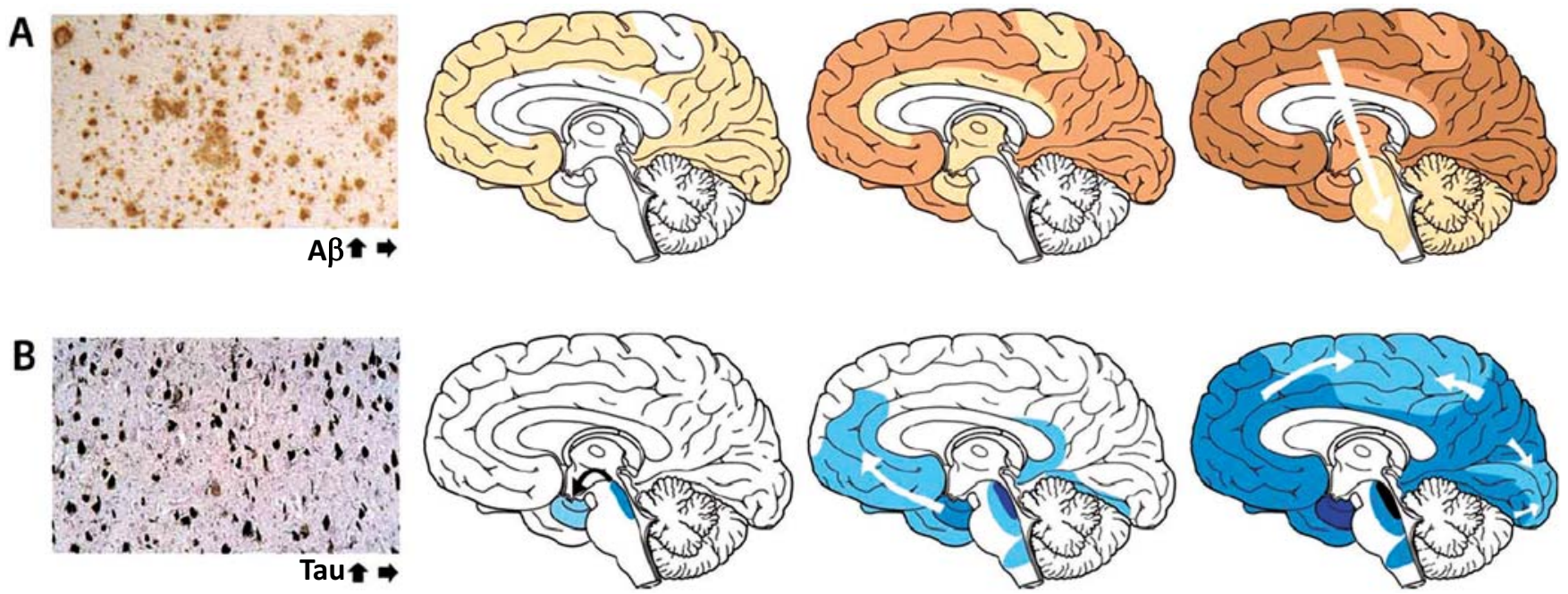

Fig. (1). The accumulation of misfolded proteins in Alzheimer disease follows characteristic and predictable patterns as illustrated by the increasing intensity and spreading of color. (A) Amyloid plaques first appear in neocortex, followed by allocortex and finally progressing to subcortical regions. The three brain schemata reflect Montine A scores $1-3$ from left to right. (B) Neurofibrillary tangles appear first in the allocortex of the medial temporal lobe and spreads to the associative isocortex, relatively sparing the primary sensory, motor, and visual areas. The three brain schemata reflect Montine B scores $1-3$ from left to right. Reprinted with permission from [52].

In stage I, NFT appear consistently in the (trans)entorhinal cortex, along with the CA1 region of the hippocampus in stage II. Thereafter, limbic structures become affected, such as the subiculum of the hippocampal formation (stage III), the amygdala, thalamus, and, claustrum (stage IV). Finally, NFT spread to virtually all isocortical areas (isocortical stage), with the associative areas being affected prior and more severely (stage $\mathrm{V}$ ) than the primary sensory, motor, and visual areas (stage VI). Notably, NFT lesions in striatum and substantia nigra might occur during the late isocortical stage. The stellate neurons of layer II, the superficial portion of layer III, and, the large multipolar neurons of layer IV of the entorhinal cortex are preferentially lesioned, whereas the same applies to mainly layers III and $\mathrm{V}$ of the isocortical areas [53, 54]. As mentioned before, the Braak staging approach of NFT in AD brain has recently been included in the overall "ABC" scoring consensus of Montine et al. [56]. The NFT-based B score refers to the Braak staging as follows: $\mathrm{B}$ score $0=$ stage 0 ; $\mathrm{B}$ score $1=$ stage I or II; B score $2=$ stage III or IV and B score $3=$ stage V or VI.

\subsection{Other Protein Inclusions}

The misfolding, aggregation and accumulation of proteins in the brain, resulting in synaptic dysfunction and neuronal loss is a seminal pathological mechanism in diverse neurodegenerative diseases [65]. Although the distribution and composition of prion-like protein aggregates are considered different in each neurodegenerative disease [65], AD brain may also contain other types of protein deposits besides amyloid plaques and NFT. More than $50 \%$ of AD patients also exhibit abundant accumulation of $\alpha$-synuclein ( $\alpha$ Syn)-positive Lewy bodies [66] and are termed the Lewy body variant of $\mathrm{AD}$, which typically exhibits an accelerated disease course and a more pronounced cognitive decline than pure $\mathrm{AD}$ patients $[67,68]$. It has been hypothesized that $\mathrm{A} \beta$ and a-Syn can interact synergistically thereby accelerating the pathology and cognitive decline [69], although it has also been postulated that a-Syn can be neuroprotective against $\mathrm{A} \beta$-induced cell death, suggesting a cell defense mechanism during the initial stages of the mixed pathology [70].

The dominantly inherited polyglutamine (polyQ) diseases, such as Huntington disease and spinocerebellar ataxias, are caused by unstable trinucleotide repeat expansions, leading to pathogenic glutamine tracts in particular proteins [71]. Expansions within the polyQ tract of the TATA box-binding protein (TBP), an essential transcription factor, result in accumulation of the protein in various polyQ diseases. A CAG/CAA repeat expansion in the TBP gene, for example, may cause spinocerebellar ataxia with associated features such as dementia and/or psychiatric manifestations [72]. Also in AD brain, TBP accumulation has been observed within NFT structures, with variable levels between patients, across brain areas and relative to tau and $A \beta$ [73].

Patients with amyotrophic lateral sclerosis have aggregates mainly composed of superoxide dismutase 1 (SOD1) in cell bodies and axons of motor neurons [74]. SOD1, a ubiquitously expressed antioxidant enzyme that plays a key role in the cellular defense against harmful superoxide radicals, is however also a major target of oxidative damage in $\mathrm{AD}$ which forms proteinaceous aggregates that are associated with amyloid SP and NFTs in AD brains [75].

The ubiquitin proteasome system (UPS) is a highly regulated mechanism of intracellular protein degradation and turnover and thus plays a role in a variety of cellular functions. Dysregulated ubiquitination and protein clearance has been implicated in various neurodegenerative disorders, including $\mathrm{AD}$ [76]. Ubiquitinated forms of tau and $\mathrm{A} \beta$, as well as other ubiquitinated proteins, are major components of the AD-typical protein aggregates [77-79]. Components of the UPS could be linked to the early phase of AD, marked by 
synaptic dysfunction, as well as to the late stages of the disease, characterized by neurodegeneration $[78,79]$.

Initially, transactivation responsive region (TAR)-DNAbinding protein 43 (TDP-43) was considered to be a diseasespecific component of ubiquitin-positive and tau-negative inclusions in the brains of patients with frontotemporal lobar degeneration with ubiquitin-positive inclusions and amyotrophic lateral sclerosis [80]. However, it is now widely known that this protein can also abnormally concomitantly accumulate in other neurodegenerative diseases, including $\mathrm{AD}$ with a prevalence of approximately $30 \%$, variable distribution patterns and a modified clinicopathologic and radiologic AD phenotype [81-83]. TDP-43 pathology is thought to be triggered by $A \beta$, independent of tau [84].

\subsection{Neuroinflammation}

Clinical manifestations preceding the dementia stage support an early and substantial involvement of an innate neuroimmune response in AD pathogenesis [85-87]. The two major inflammation-related cellular players are microglia and astrocytes. Microglia have crucial physiological functions in the brain, including tissue surveillance and synaptic remodeling [88], which may be compromised by A $\beta$ species inducing a dystrophic microglia phenotype, reducing phagocytic capacity, and eliciting an increased cytokine production $[89,90]$. Analogously, since the physiological role of astrocytes has been linked to fluid, ion, $\mathrm{pH}$, and transmitter homeostasis, synapse function, regulation of blood flow and energy and metabolism, astrocytic atrophy leading to a detriment of neuronal support may play a role in AD-related symptomatology $[87,91]$. Initially, the acute inflammatory response is thought to aid clearance and restore tissue homeostasis. Triggers (e.g. pathological ageing with sustained exposure to $A \beta$, genetic mutations) and aggravators (e.g. peripheral inflammation, obesity, brain trauma) promote sustained immune activation, which ultimately leads to chronic neuroinflammation. Pathological accumulation of $\mathrm{A} \beta$ is considered a key player in the activation of microglia and astrocytes in AD brain that leads to the upregulation of a myriad of mediators and modulators of neuroinflammation $[87,92]$. These include among others, cytokines [92], adhesion molecules and chemokines [93, 94], caspases [95], prostaglandins [96], complement system components [97], nitric oxide and reactive oxygen species [98], and induce alterations to the neurovascular unit [99], which can be detrimental to neuronal functioning. Perpetuation of glial activation causes functional and structural changes that result in neuronal degeneration and scar formation [87, 100]. Although neuroinflammation plays a pivotal role in $\mathrm{AD}$ pathogenesis, detection of inflammatory markers in CSF, blood or directly in the brain via imaging paradigms, has not yet been established as a valuable and validated diagnostic method and progression monitor [87], let alone the potential link between neuroinflammation and NPS in AD. Nevertheless, the involvement of (neuro)inflammation in psychiatric disorders [101] and $\mathrm{AD}$ indicates its possible involvement underlying NPS in AD. Therefore, in subsequent sections, relevant studies assessing neuroinflammatory mediators of NPS will be dealt with where relevant.
It has been previously evidenced that dense-core amyloid plaques are commonly associated with reactive astrocytes and microglial cells $[102,103]$. The latter indicates that $\mathrm{A} \beta$ might be the major trigger of this response, even though a highly significant positive correlation between both astrocytosis and microgliosis and NFT burden, and not amyloid plaque burden, has been found as well [104].

\subsection{Neuronal and Synaptic Loss}

The mechanisms underlying AD-related neuronal and synaptic loss are very complex and different in nature. Accumulated $A \beta$ induces multiple cytotoxic effects, such as oxidative stress, changes in ionic homeostasis, alterations in enzymatic kinase activity, and hyperphosphorylation of tau protein. Subsequently, apoptosis, activation of glutamate receptors, DNA damage, and, elevation of intracellular calcium levels may occur [105-108]. Eventually, all these A $\beta$ induced events may directly or indirectly induce neuronal death. However, the quantity of $\mathrm{A} \beta$ deposits does not necessarily correlate with clinical features of patients, since SP are also found in the brain of elderly without AD [109]. In addition, accumulation of SP is not associated with the amount of synaptic loss $[110,111]$, nor with clinical disease severity. Moreover, because the spatiotemporal and laminar pattern of synapse loss matches that of neuron loss, and, concurrently, synaptic loss even exceeds the existing neuronal loss within a particular cortical area, it becomes very likely that synapse loss precedes neuronal loss indeed. Probably this is also why synaptic density is the best pathological correlate of cognitive decline in AD [112-114]. Synaptic alterations in AD are associated with dendritic pathology $[115,116]$. Dendritic degeneration and loss in AD brain has been described mostly in the perirhinal and entorhinal cortices [54], in the hippocampus, particularly in the subiculum, where the dendritic arborization index was substantially decreased by up to $66 \%$ [117], as well as in various other cortical areas [118-121].

Although neurotoxicity of $A \beta$ has initially been attributed to its fibrillary forms, later studies showed that neurotoxins also comprise small diffusible $A \beta$ oligomers, called $A \beta-$ derived diffusible ligands (also referred to as ADDLs) [23]. The presence of high-affinity ADDL-binding proteins in hippocampus and frontal cortex, but not cerebellum parallels the regional specificity of $\mathrm{AD}$ pathology and suggests the involvement of a toxin receptor-mediated mechanism [108]. Moreover, posttranslational changes to $\mathrm{A} \beta$ peptides i.e. nitration, oxidation, phosphorylation, isomerization, pyroglutamylation, racemization, and glycosylation, affects their biochemical properties and functions in the pathophysiology of $\mathrm{AD}$ [122].

\section{BRAIN CIRCUITS, NETWORKS AND SYSTEMS INVOLVED IN REGULATION OF BEHAVIOUR}

The fact that with progression of the disease, AD affects nearly all brain regions, including the epicenters of emotions and cognition and their extensive and reciprocal neuronal connections, forms a logical foundation for the development of both cognitive and NPS-related manifestations. Increasing knowledge in behavioral neuroscience and the neurocircuitry underlying cognitive and various noncognitive functions over the last decades, has founded the basis for the develop- 
ment of theoretical models describing the neurobiological underpinnings of NPS in AD [2], with the three major models being (i) the frontal-subcortical circuitry [123, 124]; (ii) cortico-cortical networks [125], and (iii) the ascending monoaminergic hypothesis [126].

\subsection{Frontal-Subcortical Circuitry}

The frontal-subcortical circuitry model is based on Geschwind's theory of disconnection syndromes stating that these higher function deficits resulted from white matter lesions or lesions of the association cortices, the latter acting as relay stations between primary motor, sensory and limbic areas [127]. The prototypic structure of all circuits is an origin in the frontal lobes, projection to striatal structures, connections from striatum to globus pallidus and substantia nigra, projections from these two structures to specific thalamic nuclei, and a final link back to the frontal lobe. In addition to a motor and an oculomotor circuit, at least three frontal-subcortical circuits mediate human behavior: (i) the dorsolateral prefrontal circuit mediating planning, organization, and executive function, (ii) the lateral orbitofrontal circuit mediating inhibitory control, and, (iii) the anterior cingulate circuit mediating motivated behavior (Fig. 2; [124]).

\subsection{Cortico-Cortical Network}

The cortico-cortical network model posits that the human brain consists of five partially segregated and partially overlapping large-scale neurocognitive networks: (i) a right hemisphere-dominant spatial awareness network with epicenters in the dorsal posterior parietal cortex, the frontal eye fields and the cingulate region; (ii) a left hemispheredominant language network with epicenters in Wernicke's and Broca's areas; (iii) a memory-emotion network with epicenters in the hippocampal-entorhinal regions and the amygdaloid complex; (iv) a working memory-executive function network with epicenters in the prefrontal cortex and probably the posterior parietal cortex; (v) a face and object identification network with epicenters in the midtemporal and temporopolar cortices [125]. These large-scale networks are composed of widely separated and interconnected local networks that address the neurobiological basis of complex cognitive domains.

The functionality of the memory-emotion network is based on the widely distributed but tightly interconnected limbic structures [125], that were originally described in the first half of the $20^{\text {th }}$ century by C. Jakob (1906), J. Papez (1937), P. Yakovlev (1948) and P. MacLean (1949, 1952).

\section{Dorsolateral prefrontal circuit}

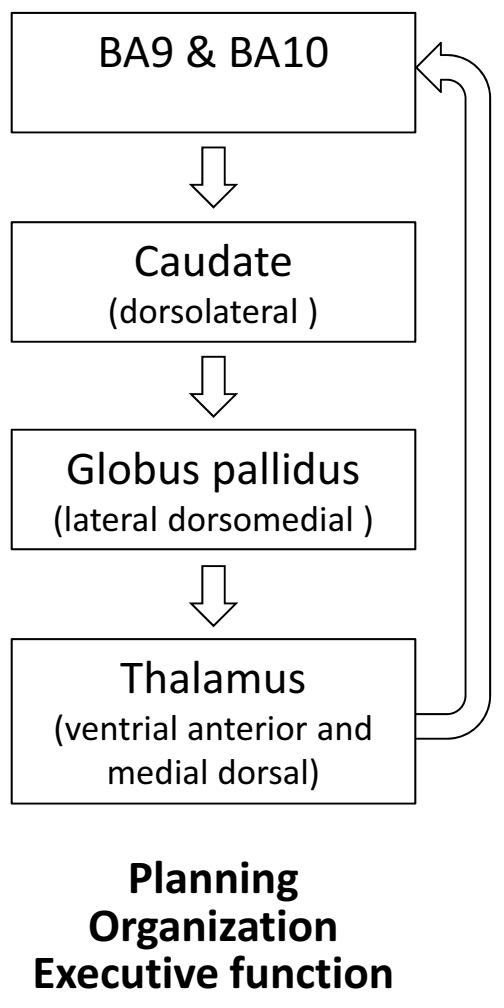

Lateral orbitofrontal circuit

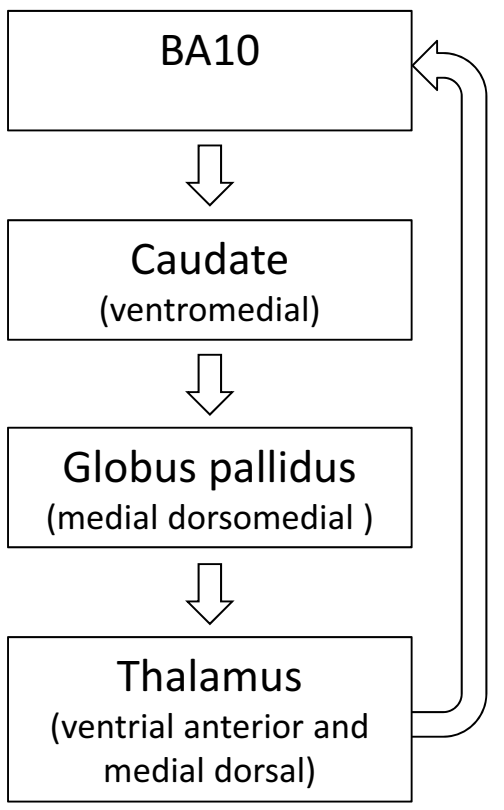

Inhibitory control

\section{Anterior cingulate circuit}

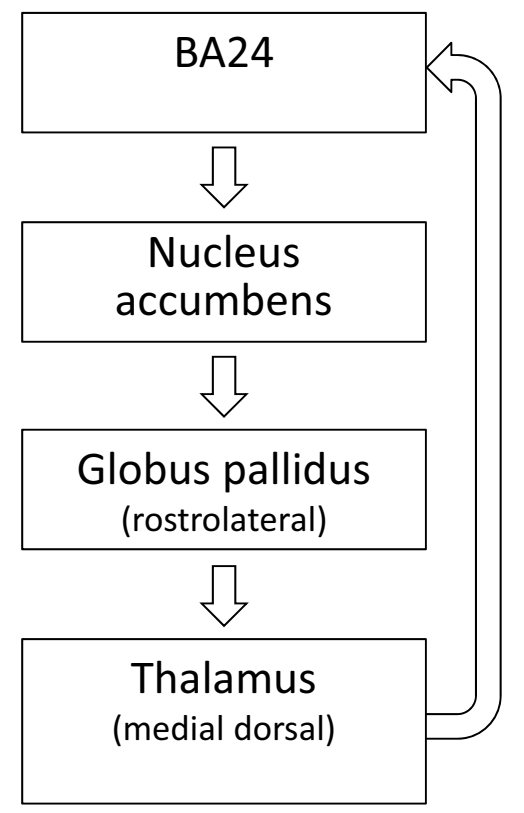

\section{Motivated behaviour}

Fig. (2). At least three frontal-subcortical circuits mediate human behavior: (i) the dorsolateral prefrontal circuit mediating planning, organization, and executive function, (ii) the lateral orbitofrontal circuit mediating inhibitory control and (iii) the anterior cingulate circuit mediating motivated behavior. The prototypic structure of all circuits is an origin in the frontal lobes, projection to striatal structures, connections from striatum to globus pallidus and substantia nigra, projections from these two structures to specific thalamic nuclei, and a final link back to the frontal lobe. Indirect pathways projecting from striatum to globus pallidus externa, then to subthalamic nucleus, and back to the globus pallidus interna/substantia nigra, as well as connections of the substantia nigra and the subthalamic nucleus are not shown for. Legend: BA, Brodman area. Adapted from [124]. 
The subcortical limbic structures include the amygdala, mammillary bodies, hypothalamus, specific thalamic nuclei (anterior, intralaminar, and medial dorsal groups) and the ventral striatum (nucleus accumbens). The cortical limbic components can be separated into limbic and paralimbic zones that display increasing anatomical complexity, ranging from the corticoid areas of the amygdaloid complex, substantia innominata, septal and olfactory nuclei, over the allocortex of olfactory and hippocampal regions, up to the paralimbic or mesocortex including the piriform cortex, entorhinal cortex, the parahippocampal cortex on the medial surface of the temporal lobe, and the cingulate cortex [128].

Based on functional imaging data and insights from neurological disorders associated with limbic pathology, the limbic network model has recently been updated and further divided in (i) the hippocampal-diencephalic and parahippocampal-retrosplenial network dedicated to memory and spatial orientation; (ii) the temporo-amygdala-orbitofrontal network for the integration of visceral sensation and emotion with semantic memory and behaviour; (iii) the default-mode network involved in autobiographical memories and introspective self-directed thinking. Table $\mathbf{1}$ summarizes the functions of these limbic networks, the stage they become affected in $\mathrm{AD}$ and corresponding symptomatology.

\subsection{The Ascending Monoaminergic Hypothesis}

As extensively reviewed by Trillo et al. [126], the ascending monoaminergic system with cell bodies in the brain stem diffusely projecting via long axons to virtually all parts of the brain is involved in many aspects of behavior. For extensive illustration of the different monoaminergic pathways, we refer to the highly detailed first three figures included in the review by Trillo et al. [126].

The ascending dopaminergic system has been classically divided in the nigrostriatal pathway originating in substantia nigra and targeting striatum (caudate-putamen), and the mesolimbic and mesocortical pathways originating in the ventrotegmental area and projecting towards limbic region and cortical regions, respectively. In more detail, the mesencephalic dopaminergic system targets cortical and subcortical structures including the medial and dorsolateral prefrontal cortex, orbitofrontal cortex, anterior cingulate cortex, dorsal and median raphe nucleus, tuberomammilary nucleus, nucleus basalis of Meynert, the external segment of the globus pallidus, putamen, caudate nucleus, medial septum, amygdala, entorhinal cortex, and dentate gyrus. The main norepinephrinergic projections arise from neuronal population in the locus coeruleus which widely project to the telencephalon, including the olfactory bulb, hippocampus, amygdala, thalamus, hypothalamus, ventral striatum, basal forebrain (nucleus basalis of Meynert) and various (neo)cortical areas, among which anterior cingulate cortex, orbitofrontal cortex and dorsolateral prefrontal cortex. Finally, ascending serotonergic fibers arise from the raphe nuclei, which target (neo)cortical areas (for example anterior cingulate cortex, orbitofrontal cortex and dorsolateral prefrontal cortex), hippocampus, striatum (caudate nucleus and putamen) and the external segment of the globus pallidus,

Table 1. Functional-anatomical division of the limbic system into three distinct but partially overlapping networks and corresponding functions and involvement in Alzheimer's disease.

\begin{tabular}{|c|c|c|c|}
\hline Limbic Network & Functions & \multicolumn{2}{|c|}{ Relevance in Alzheimer's Disease } \\
\hline $\begin{array}{l}\text { Hippocampal- } \\
\text { diencephalic and } \\
\text { Parahippocampal- } \\
\text { retrosplenial network }\end{array}$ & $\begin{array}{l}\text { - Memory } \\
\text { - Spatial orientation }\end{array}$ & $\begin{array}{l}\text { Early-stage AD } \\
\text { MCI }\end{array}$ & $\begin{array}{l}\text { - Hippocampocentric memory } \\
\text { dysfunction } \\
\text { - Anterograde and limited retro- } \\
\text { grade memory deficits } \\
\text { - Difficulties in spatial orientation }\end{array}$ \\
\hline $\begin{array}{l}\text { Temporo-amygdala- } \\
\text { orbitofrontal network }\end{array}$ & $\begin{array}{l}\text { - Behavioural inhibition } \\
\text { - Memory for temporally complex visual information } \\
\text { - Olfactory-gustatory-visceral functions } \\
\text { - Multimodal sensory integration } \\
\text { - Object reward association learning } \\
\text { - Outcome monitoring }\end{array}$ & Advanced $\mathrm{AD}$ & $\begin{array}{l}\text { - Semantic deficits } \\
\text { - Language difficulties } \\
\text { - Personality changes } \\
\text { - NPS (e.g. aggression, disinhibi- } \\
\text { tion) }\end{array}$ \\
\hline
\end{tabular}

Legend: AD: Alzheimer's disease; MCI: mild cognitive impairment; NPS: neuropsychiatric symptoms. Adapted from [128]. 
medial septum, thalamus and hypothalamus, and the tuberomammillary nucleus.

Overall, monoaminergic fiber projections are composed of generally poorly myelinated axons to innervate the extensive forebrain (including the cortex, basal ganglia, thalamus, and amygdala) [129]. However, in order to innervate a disproportionately high number of neurons, a selected number of monoaminergic cell bodies make use of a particular method of innervation called "volume transmission", as opposed to standard synaptic innervation or "wire transmission". According to this theory, monoaminergic neurons are able to induce modulatory and trophic effects on a large number of neighboring cells through diffusion to distant extra-synaptic sites [129]. By combining wire and volume transmission-based innervation, the monoaminergic system imposes a strong modulatory influence on most of the regions of the brain, and, hence many aspects of behavior [126]. Moreover, different monoaminergic systems share similar input and output regions and directly project to each other, thereby further substantiating the highly complex and selective modulatory functions of these systems.

\section{STUDIES LINKING PATHOLOGY - NPS}

Over time, the AD-affected brain shrinks dramatically due to widespread cell death, affecting consequently nearly all its functions. Whole brain atrophy rates differ among normal aging individuals and those diagnosed with mild cognitive impairment (MCI) and AD [130]. The spatial pattern of neocortical atrophy associated with normal versus pathologic aging is not uniform and depends on the degree of disease severity (Fig. 3) [131-134]. Atrophy is not uniform across cortical and subcortical regions (Fig. 3), nor does it follow a linear trajectory [135]. The spatial pattern and rate of decline across the spectrum from normal aging to $\mathrm{AD}$ is of course paralleled by the development of various cognitive, functional and behavioral symptoms.

The different pathways, circuits and networks involved in the regulation of behavior (as described in section 3 ) are logically also affected by AD-related pathology and subsequent atrophy, which may underlie the development of cognitive and NPS-related symptomatology.

Various brain regions included in the frontal-subcortical circuits mediating human behavior (section 3.1) may be affected by $\mathrm{AD}$-related pathology leading to disturbances in the associated behavioral domains, i.e. planning, organization, and executive function, inhibitory control and motivated behavior (apathy) [136-138].

Some structures of the hippocampal-diencephalic and parahippocampal-retrosplenial network (section 3.2) are particularly vulnerable to damage caused by viral infections or alcohol, leading to for example encephalitis or Korsakoff's syndrome, respectively [128]. In addition, imaging studies have documented altered metabolism and reduced functional activation of this network also in age-related neurodegenerative disorders such as MCI and early stages of AD [139, 140], while damage to the temporo-amygdala-orbitofrontal network manifests with cognitive and behavioural symptoms characteristic of for example temporal lobe epilepsy, mood disorders, traumatic brain injury, psychopathy and neurode- generative dementias, including advanced AD [128]. Dysfunction of the dorsomedial default-mode network has been related to various neuropsychiatric disorders, including schizophrenia, epilepsy, anxiety and depression, autism, attention deficit/hyperactivity disorder and importantly, also in dementia (including MCI and AD) [141-143].

In addition to the cholinergic degeneration in AD [144], extensive neuropathological studies have established a compelling link between abnormalities in structure and function of subcortical monoaminergic systems and the pathophysiology of $\mathrm{AD}$ (for review: [126, 145]). While the rostral raphe complex is especially susceptible to NFT formation, other monoaminergic nuclei frequently exhibit both pathological markers (SP and NFT) [146]. An additional link between the monoaminergic systems and AD pathophysiology is based on genome-wide association studies indicative of relationships between polymorphisms in each monoaminergic system and AD symptomatology (for review [126]).

Brain imaging, electrophysiological, neurochemical and neuropathological approaches constitute the major tools to investigate brain-behavior relationships in general and hence also the biological underpinnings of NPS. Neuropathological studies of NPS in AD will be the primary focus in subsequent sections dealing with particular NPS, but other relevant approaches (e.g. neuroimaging or electrophysiological approaches) indicative of underlying neuropathological alterations will be briefly touched upon.

\subsection{Depression}

With prevalence clustering around $20-50 \%$, depression is one of the most frequent comorbid psychiatric disorders in $\mathrm{AD}$ with negative consequences for patients and caregivers, including faster cognitive decline, poorer quality of life, greater disability in activities of daily living and a higher mortality rate $[147,148]$. Early-onset depression $(<$ age 65 years) and recurrent depression constitute long-term risk factors for the development of dementia, whereas the onset of more recent depressive symptoms may reflect a prodromal phase of dementia [149], but the neurobiological mechanism underlying this association is not yet fully understood. Several lines of evidence suggest that depression shares complex pathophysiological routes with dementia.

Several cross-sectional studies were indicative of brain changes associated with $\mathrm{AD}$, including reduced temporal lobe [150], hippocampal, and amygdala volume [151, 152] in depressed elderly. In line with the observation that depressive symptoms may indeed be a clinical marker of prodromal $\mathrm{AD}$, depressive symptoms were found to be associated with AD-related neuroanatomical changes, particularly in white matter regions causing brain atrophy [153]. Compared to other common NPS, as for example apathy, depression is indeed considered an early sign of a more aggressive neurodegenerative process or considered to lower brain reserve capacity, allowing for more rapid progression of AD neuropathology [154]. Nevertheless, this presumed link was not observed in all studies linking depression and conversion to clinical AD. Results of Royall and Palmer [155] argue against the role of AD-related neuropathology as a mediator of depression's effect on cognitive decline, although authors could not rule out a significant mediation effect in a subset 
A)

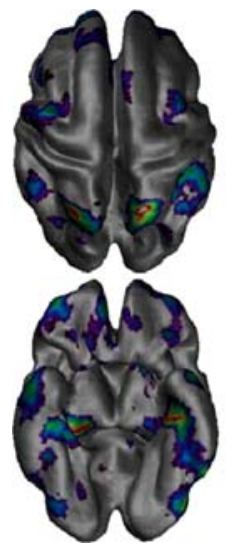

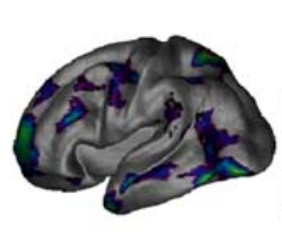

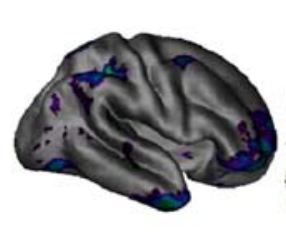

B)

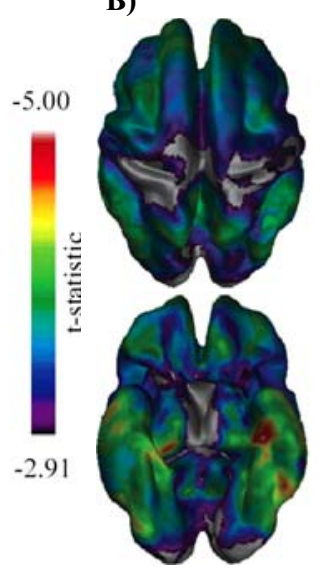

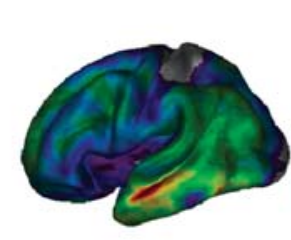

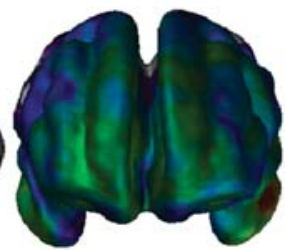

$-9.57$
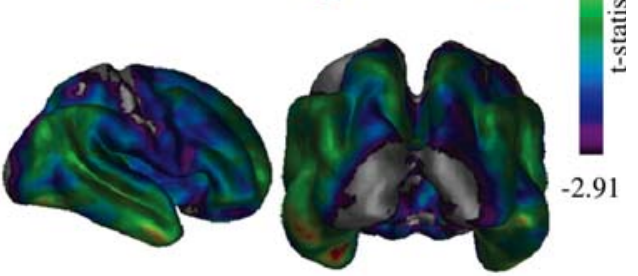

Fig. (3). Illustration of a magnetic resonance imaging-based analysis technique to determine the pattern of cortical thinning (measure of cortical atrophy) as a function of disease progression. Age-matched control individuals, mild cognitive impairment (MCI) and Alzheimer's disease (AD) groups were compared. Panel A: cortical thickness differences between the control and MCI group with the most significant difference seen in the (left) medial temporal region. Frontal and posterior parietal areas show differences in a more bilateral fashion. Panel B: Cortical thickness differences between the control and $\mathrm{AD}$ group clearly indicating bilateral medial and lateral temporal lobe differences are present bilaterally. Occipital, primary motor and primary sensory cortices show the least significant differences. Reprinted with permission from [134]. Abbreviations: AD, Alzheimer's disease; MCI, mild cognitive impairment.

of cases, perhaps with more severe baseline depressive symptoms.

A lifetime history of major depression in AD was particularly linked to increased plaque and tau-related pathological alterations within the hippocampus. Patients with concurrent major depression present at the time of first diagnosis of AD exhibited an even larger number of hippocampal amyloid plaques and NFT [159]. Default mode network dysfunction has been proposed to be an important factor in the association between depression and AD [156-159].

In addition, depression is considered to be significantly more prevalent in dementia with Lewy bodies (DLB) as compared to AD [160-163], potentially reflecting a manifestation of LB pathology. Analogously, a higher likelihood of depression has also been observed in the Lewy body variant of AD versus AD patient cohorts [164], which is apparently associated with the presence of LBs in the amygdala [165], the limbic brain region most closely associated with depression in the general population [166], or in cortical areas [165]. The presence of LBs is accompanied by neuronal cytoskeleton changes, which may influence neuronal connectivity via alterations to the synaptic network $[167,168]$.

Also other brain regions affected by AD pathology have been implicated in depression. A disproportionate loss of noradrenergic locus coeruleus neurons for example has been considered to represent an important organic substrate of depression in AD [169, 170], which was further substantiated by reduced cortical noradrenergic levels in demented patients with major depression $[171,172]$. In addition, an impaired noradrenergic neurotransmission in the cerebellar cortex might also be associated with depression in AD [173] (Fig. 4), which is in line with the fact that a wide range of NPS can be observed following cerebellar pathology [174].

Interestingly, AD-related neuroinflammation might also (at least partially) lie at the basis of certain NPS, including depression. There is for example mounting evidence that the enzyme indoleamine 2,3-dioxygenase (IDO), which metabolizes the serotonin (5HT) precursor tryptophan into kynurenine, is a prominent player in the relation between chronic inflammation and depression $[175,176]$. IDO activity is upregulated by neuroinflammatory processes, leading to kynurenine catabolization and an overproduction of quinolinic acid, the neurotoxic end product of the tryptophan pathway which may contribute to the excitotoxic effects in AD brain. Moreover, decreased tryptophan levels consequently affect 5HT synthesis, which is a neurochemical hallmark in the etiology of depression. Increased IDO activity can therefore play an important link between neuroinflammation and depression in AD [177]. Recently, a novel TNF- $\alpha$-induced proinflammatory agent, neutrophil gelatinase-associated lipocalin (NGAL) or lipocalin 2 ( $\mathrm{Lcn} 2)$, has been linked to both $\mathrm{AD}$ [178] and late-life depression [179]. Interestingly, plasma NGAL levels are significantly increased in elderly depressed patients with cognitive impairments [180] and in serum of people with DS [181], which are both known population groups at risk to develop AD. Neuroinflammation may indeed play a role in depression, or perhaps even in NPS in general.

Cerebral blood flow and metabolism appear to be reduced in depressed compared with non-depressed AD patients in (pre)frontal, temporal and parietal areas [182-187]. Depression in AD has also been associated with a significantly larger volume of right parietal white matter hyperintensities [188].

It is well established that abnormalities in serotonergic neurotransmission are central to the pathophysiology of depression in younger adults, but few studies have examined serotonergic pathological changes in elderly patients and especially in elderly patients in which depression occurs in dementia. One study found no evidence for loss of serotonergic neurons or the presence of neuritic pathology in the dorsal raphe nuclei in older people with depression, with or without comorbid AD [189], whereas significantly lower 
cortical 5-HT reuptake sites, as well as hippocampal 5HT1A receptors and serotonergic compounds were measured in depressed AD patients [172, 190-192].

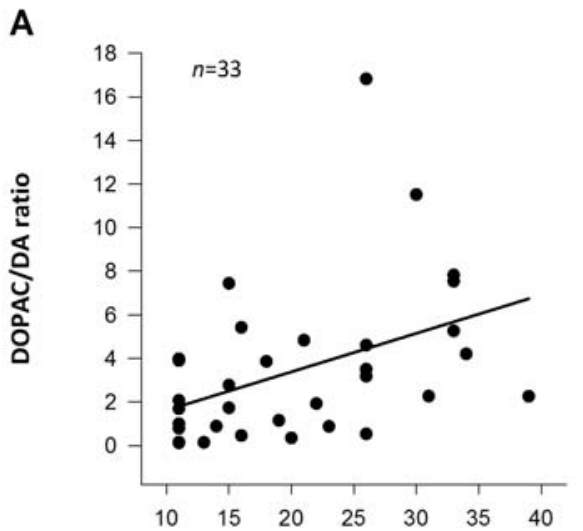

CMAI cluster 2: physically nonaggressive behavior (/77)

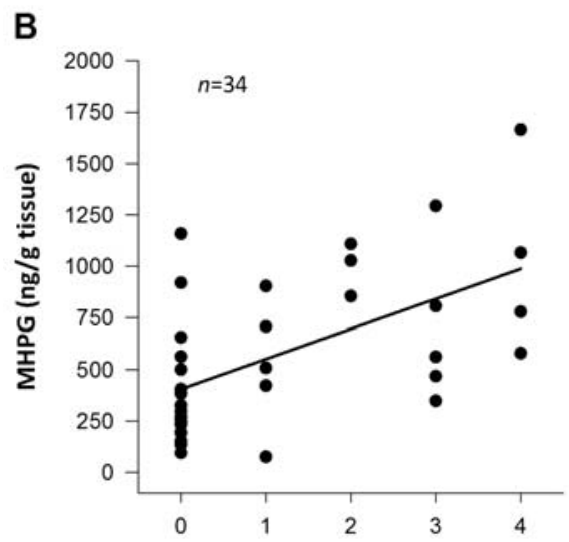

Behave-AD cluster F: affective disturbances (/6)

C

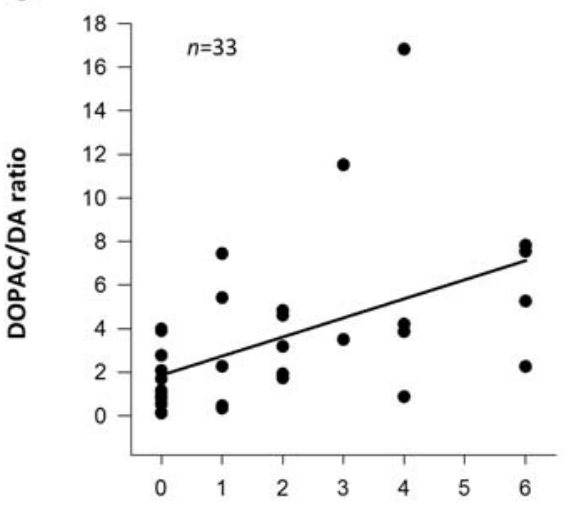

Behave-AD cluster C: activity disturbances (/9)

Fig. (4). Neurochemical correlates of neuropsychiatric symptoms (NPS) in Alzheimer's disease (AD). Scatter plots representing significant monoaminergic neurotransmitter correlates of NPS in the cerebellar cortex of autopsy-confirmed AD patients. Panel A: positive correlation between the DOPAC/DA ratio, indicative of DA turnover, and physically nonaggressive behavior $(\mathrm{R}=+0.497$; $\mathrm{p}=0.003$ ). Panel B: positive correlation between MHPG levels, the major noradrenergic metabolite, and affective disturbances
$(\mathrm{R}=+0.562 ; \mathrm{p}=0.0005)$. Panel $\mathrm{C}$ : positive correlation between the DOPAC/DA ratio and activity disturbances $(\mathrm{R}=+0.595$; $\mathrm{p}=0.00026$ ). Although the cerebellum has historically been considered to be a brain region principally involved in motor control and coordination, more recently, higher cognitive functions have been attributed to its physiological functions as well. A strong and sustained reciprocal connection between the deep cerebellar nuclei to the thalamus and then on to the (prefrontal) cerebral cortex, called cerebello-thalamic-cortical pathway, neuroanatomically accounts for the role of the cerebellum numerous behavioral processes. Cerebellar pathology and subsequent neurochemical alterations may underlie certain NPS. Abbreviations: AD, Alzheimer's disease; Behave-AD, Behavioral Pathology in Alzheimer's Disease Rating Scale; CMAI, Cohen-Mansfield Agitation Inventory; DA, dopamine; DOPAC, 3,4-dihydroxyphenylacetic acid; MHPG, 3methoxy-4-hydroxyphenylglycol. Reprinted with permission from [173].

Predictors of depression-related behavior (immobility in a forced swim test and tail suspension test) in mouse models of $\mathrm{AD}$ presumably also involve monoaminergic neurotransmitter alterations. The $3 \times \mathrm{Tg}-\mathrm{AD}$ model displays lower basal extracellular output of monoamines in the frontal cortex and ventral hippocampus, accompanied by obvious local $A \beta$ and tau pathology [193].

\subsection{Apathy}

With reported prevalence rates up to almost $80 \%$, apathy is the most common and persistent NPS in AD $[5,194]$. It is defined as diminished motivation for at least 4 weeks, accompanied by two of the following symptoms: reduced goaldirected behavior, reduced goal-directed cognitive activity, and reduced emotions [9]. Several studies have indicated an overlap between apathy and executive dysfunction [195, 196], both presumably related to dysfunction of thalamicprefrontal-subcortical circuitry. Since the basal ganglia and their connections with prefrontal cortex are essential to decision-making, fronto-striatal circuit dysfunction may be responsible for the emergence of apathetic behavior in a wide range of neurological disorders [197].

Apathy is rather difficult to isolate from depression given the frequent comorbidities and a considerable overlap in key symptoms [194]. Nevertheless, apathy can occur without depression in $\mathrm{AD}$ and when depression and apathy co-occur in AD patients, both NPS have been shown to be clinically and anatomically independent [198, 199]. Response to treatment is also different: antidepressants, in particular selective serotonin reuptake inhibitors (SSRI), seem to have no therapeutic benefit in apathetic patients or can even increase the apathy severity [200], which may be indicative of differential underlying neurobiological and neurochemical substrates.

Evidence from MCI patients and pre-dementia depressive syndromes has led to the hypothesis that in early AD, apathy may be the result of dysfunctional affective-emotional processing [201], which takes place in ventromedial prefrontal cortex, and its connections with amygdala and nucleus accumbens. Correspondingly, neuropathological progression in AD targets ventromedial parts of frontal cortex in an early stage [202-204]. Apathetic patients have been shown to dis- 
play significantly greater NFT burden and cortical thinning in left caudal anterior cingulate cortex and left lateral orbitofrontal cortex, as well as left superior and ventrolateral frontal regions, than AD patients lacking apathy symptoms [205-207].

Involvement of the anterior cingulate and related frontosubcortical structures, indicative of default mode network dysfunction, in patients with apathy has also been confirmed in various imaging studies [188, 208-210].

Besides imaging studies, also several postmortem studies support the hypothesis that dopaminergic circuits linking the basal ganglia with the anterior cingulate and frontal cortices, default mode network structures, normally involved in motivation and reward, may be dysfunctional in people with AD and apathy [211, 212]. For example, decreased dopamine levels have been reported in the mesolimbic and mesocortical pathway [213-215], as well as changes in dopamine receptor density and distribution in apathy-related brain regions [216-218].

Pharmacological interventions have also indicated that cholinergic mechanisms may underlie the development of apathy. Improvements in apathy have been noted following cholinesterase inhibitor treatment which has been associated with activation of the ventral striatum [219, 220].

\subsection{Agitation and Aggression}

The prevalence of agitation and aggression has been reported to range from $48 \%$ to $80 \%$ in $\mathrm{AD}$ patients with persisting symptoms over months and occurring across all AD stages [221, 222]. Especially physical aggression is a common cause for institutionalization and an important factor in overmedication and the use of physical restraint [223].

Agitation and aggression in AD have been associated with brain changes in frontal and limbic regions including amygdala, cingulate cortex, and insula. Increased burden of NFT in the orbitofrontal cortex has been linked to agitation and aberrant motor behavior, latter defined as fidgeting, wandering, pacing or rummaging [205], while aggressive behaviors have been associated with neuronal loss in the rostral noradrenergic locus coeruleus [224]. Also increased hippocampal NFT load was associated with increased severity of aggressive behaviors and presence of chronic aggression [225]. Aggressive AD subjects were also shown to display significant hypoperfusion in the left anterior [226] and right medial temporal cortex [227]. Greater AD pathologyrelated amygdala atrophy was also associated with more prominent aberrant motor behavior [228]. Both agitation and aggression in MCI and AD have been associated with neurodegeneration affecting the anterior salience network, in particular greater atrophy of frontolimbic regions, right posterior cingulate, and left hippocampus, that may reduce capacity to process and regulate behaviors properly [229].

Cholinergic deficits appear more severe in AD patients displaying agitation or aggression [230]. In particular, loss of choline acetyltransferase and acetylcholinesterase enzyme activity has been reported in association with this particular NPS item [219, 230, 231]. Additional evidence comes from the robust clinical improvement of aggression or agitation observed in $\mathrm{AD}$ patients receiving cholinesterase inhibitors
[219, 232, 233]. Several neurochemical studies have also linked serotonergic alterations with aggression. Specifically, reduced levels of 5HT and its metabolites were measured in the frontal lobes of aggressive AD patients [234], in addition to preserved or up-regulated serotonin re-uptake (5-HTT) sites in hippocampus [192], and an inverse correlation between hippocampal 5-hydroxyindoleacetic acid (5-HIAA; main metabolite of 5-HT) levels and agitation scores [173]. In addition, the prolactin response to d,1-fenfluramine as an index of central serotonergic function positively correlated to agitation and aggression scores in probable AD patients with severe cognitive impairment and behavioral disturbance, moreover, having interactions with gender and cognitive impairment [234]. Serotonin transporter (5-HTT) generelated polymorphisms have been studied with regard to aggression and agitation in AD [235-237]. One study reported significant associations between the presence of 5-HTT variable number of tandem repeats sequence allele 10 and NPS or aggressiveness, but failed to show a link with the 5-HTTlinked polymorphic region (5-HTTPR), whereas another study indicated the 5-HTTPR polymorphism to confer risk for a combined psychotic and aggressive AD phenotype.

On the other hand, dopaminergic alterations may also lie at the basis of aggression/agitation in AD; an increased cerebellar dopaminergic turnover was linked to physically agitated behavior [173] (Fig. 4). A preservation of cerebellar TH-positive fibers in physically agitated AD subjects, might correspond to preserved (or even upregulated) dopaminergic neuronal endings or fiber sprouting [238]. In addition, the fact that dopaminergic turnover correlated with frontal lobe symptoms [173], is potentially indicative of a disrupted cerebello-thalamic-cortical circuit since the cerebellum might modulate aggressive/agitated behavior in AD by influencing prefrontal circuits [238].

\subsection{Anxiety and Phobias}

Anxieties and phobias in AD have been classically divided into four categories: (1) anxiety regarding upcoming events, for which the term 'Godot syndrome' was introduced, (2) other anxieties, e.g. regarding money, (3) fear of being left alone, and (4) other phobias, such as fear of bathing [3]. Furthermore, physical signs of anxiety are restlessness, pacing and stereotyped behavior. Alternative postulated signs of anxiety include sudden feelings of panic and worrying thoughts [239]. Results from the Cache County study indicated that $7.9 \%$ of patients with $\mathrm{AD}$ suffered from anxiety [240], whereas a Belgian study reported that $29.8 \%$ of AD patients were affected by anxieties and/or phobias. This difference might be due to distinct assessment scales and study populations [241].

There are few studies on structural or metabolic correlates of anxiety in AD. A relatively preserved amygdala volume has been associated with the development of anxiety and irritability in AD, which is in agreement with the relationship between the amygdala and anxiety-related behaviors in non-AD subjects with primary anxiety disorders. In the setting of a reduced ability to interpret the environment and regulate emotional responses, $\mathrm{AD}$ patients with relatively preserved amygdala function may exhibit heightened and possibly less differentiated emotional responses that seem 
inappropriate to caregivers, such as anxiety and irritability [228]. Anxiety scores correlated with lower metabolism in bilateral entorhinal cortex, anterior parahippocampal gyrus, and left superior temporal gyrus and insula [242].

Structural, morphological, and cellular alterations in the hippocampus, including among other, a reduced number of pyramidal and granular neurons, a decrease in presynaptic synaptophysin density, and decreased astrocyte complexity, in the absence of $A \beta$ plaques, were associated with cognitive impairment, but also with elevated anxiety scores in the transgenic PDAPP-J20 mouse model of AD [243].

\subsection{Psychosis}

Psychosis is a common (prevalence 30-50\%) and difficult to treat symptom in $\mathrm{AD}$ causing diminished quality of life and caregiver distress. Symptoms of AD psychosis are delusions, hallucinations and misidentifications. Criteria for psychosis of $\mathrm{AD}$ were proposed by Jeste et al. and include: characteristic delusions or hallucinations in the presence of possible or probable $\mathrm{AD}$; onset of the psychotic signs after onset of other dementia symptoms; psychotic symptoms present intermittently for at least 1 month; symptoms severe enough to cause disruption of patients' or others' functioning; symptoms not occurring only during a delirium; and symptoms not better accounted for by another psychotic disorder, medical condition or drug [244]. Although some level of pathology is necessary to give rise to psychoses, patients need to be moderately intellectually preserved in order to elaborate the context of their delusions [245].

As for depression, psychosis, and particularly visual hallucinations and delusions, seem to have different pathological substrates in DLB versus AD. In AD patients a significant positive association between the presence of neocortical NFT and the occurrence of psychotic symptoms, defined as either visual hallucinations or delusions, was described [246], while an inverse association between visual hallucinations and NFT staging was observed in DLB [247]. Interestingly, in patients with presumed Lewy body variant of AD (Braak staging V-VI; Montine B score $=3$ ), the frequency of persistent visual hallucinations was more similar to the AD compared to the DLB group (Braak staging 0-VI) [247], analogously to other studies linking the presence of cortical LB to visual hallucinations and delusions in AD [248].

Visual hallucinations in AD have been linked to lesions in and atrophy of occipital cortex (visual cortex and association areas) compared to $\mathrm{AD}$ patients without visual hallucinations [249, 250], while delusions have been linked to atrophy in frontal, temporal and limbic regions, including also hippocampus [206, 251]. Delusional misidentification symptoms in particular have been linked to right frontal lobe atrophy, a reduced number of CA1 pyramidal cells [245, 252], as well as white matter changes in the bilateral frontal or parieto-occipital region and left basal ganglia [253], while delusions and hallucinations were observed in AD patients with less cell loss in the parahippocampal gyrus and the dorsal raphe nucleus [252]. Zubenko et al. studied neuropathological and neurochemical correlates of psychosis in AD [254]. Psychosis (defined as the presence of delusions or hallucinations) was associated with significantly increased densities of SP and NFT in the prosubiculum and middle frontal cor- tex, respectively, with trends toward increased densities of these lesions in the superior temporal and the entorhinal cortex. Noradrenergic, dopaminergic and serotonergic compounds were measured in the same four cortical regions, as well as in the substantia nigra, thalamus, amygdala, and caudate nucleus. Psychosis was also associated with the relative preservation of norepinephrine in the substantia nigra, with trends in this direction for the majority of the remaining brain regions examined, and a significant reduction of 5HT in the prosubiculum that was accompanied by trends toward reduced levels of serotonin and 5HIAA in the remaining regions [254]. Disruption of a cohesive noradrenergic locus coeruleus-thalamus linked system, due to advanced locus coeruleus neurodegeneration, has been proposed to potentially lead to psychotic-like behavior in AD [173], which was, at least partially, substantiated by the observation that thalamic MHPG (i.e. 3-methoxy-4-hydroxyphenylglycol, a major noradrenergic metabolite) levels inversely correlated with hallucinations in $\mathrm{AD}$ [173].

Also cholinergic alterations have been linked to psychosis; An increase in M2 muscarinic cholinergic receptors was noted in frontal and temporal cortices of $\mathrm{AD}$ patients with psychotic symptoms [255]. Moreover, treatment with cholinesterase inhibitors also reduced psychotic symptoms in addition to their documented benefits on cognition and global function [232, 233, 256].

Recently, a decreased dopaminergic neurotransmission and increased dopaminergic catabolism, specifically in the amygdala, was suggested to function as a monoaminergic substrate of psychosis in AD, whereas a generally increased dopaminergic neurotransmitter activity in the prefrontal, temporal and mesolimbic cortices, as well as locus coeruleus and hippocampus, could closely relate to psychosis in DLB. The complexity of an altered coupling between serotonergic and dopaminergic pathways might, additionally, also account differently for the presence of psychosis in DLB compared to that in $\mathrm{AD}$ [257].

Overall, patients with AD who manifest psychosis may have disproportionate dysfunction of frontal lobes and related subcortical and parietal structures [258]. Moreover, stronger right hemispheric dysfunction in frontal and limbic regions [259], as well as in the temporal horns [260] has been associated with the presence of psychosis in AD. Delusional misidentification symptoms have been linked to hypometabolism in paralimbic (orbitofrontal and cingulate areas bilaterally) and left medial temporal areas, and significant bilateral normalized hypermetabolism in sensory association cortices (superior temporal and inferior parietal) without right left asymmetry [261]. Pronounced brain dysfunction associated with psychosis was also substantiated by electroencephalogram (EEG) abnormalities [262, 263], with spectral analysis indicating increased delta [262, 263], and theta [262] activity, in addition to decreased alpha power [263].

\subsection{Sleep and Circadian Rhythm Disturbances}

Age-related circadian alterations, with decreased amplitude of the rhythm as well as alterations in circadian phase [264], are further exacerbated in AD, making sleep disorders common behavioral disturbances in $\mathrm{AD}$, with $25 \%$ to $50 \%$ of 
patients experiencing major sleep problems and almost $75 \%$ sleeping for extended periods during the day [265]. Increasing evidence suggests that alterations in circadian rhythms can have profound consequences on emotional behavior and mental health. Disrupted circadian rhythms are also linked to the development of other NPS, such as agitation and restlessness, verbal outbursts, wandering, physical threats, and aggression, often referred to under the umbrella term "sundowning" since they mainly occur during late afternoon and evening [266].

The hypothalamic suprachiasmatic nucleus ( $\mathrm{SCN})$ is considered to be the endogenous clock of the brain. Circadian rhythms not only govern sleep-wake cycles but also rhythms in cognitive processes including subjective alertness, mathematical ability, and memory [267]. The SCN displays a senescence-related decrease in volume, which is especially pronounced in AD [268]. Degenerative changes in the SCN include neuronal loss and NFT, whereas amyloid plaques are only seldom noted in the SCN [269]. Nevertheless, indices for amyloid deposition (i.e., cerebrospinal fluid $A \beta_{1-42}$ levels) in the preclinical stage of AD appeared to be associated with worse sleep quality [270]. Recently, cortical A $\beta$ pathology was associated with impaired generation of non-rapid eye movement slow wave oscillations that, in turn, predicted disturbed long-term hippocampus-dependent memory consolidation [271].

Several lines of evidence implicate alterations in melatonin levels in $\mathrm{AD}$ as a possible neurochemical mediator of circadian changes. Interestingly, in addition to melatonin's ability to regulate circadian rhythms [272], melatonin has also been demonstrated to be a potent antioxidant and neuroprotector against oxidative stress and $A \beta$-based toxicity [273]. CSF melatonin levels decrease with the progression of AD neuropathology, already in cognitively intact subjects with the earliest AD neuropathology (Braak stages I-II, i.e. preclinical AD) [274]. Decreased night-time melatonin in the pineal gland of AD brain is accompanied by neurotransmitter abnormalities relevant to melatonin regulation [275]. More specifically, Braak stage-dependent dysregulation of pineal $\beta 1$-adrenergic receptor mRNA and the increased monoamine oxidase A activity, as reflected by the 5-HIAA:5-HT ratio, and mRNA levels were held responsible for the disappearance of the melatonin diurnal rhythm and the decrease of nocturnal melatonin synthesis in preclinical AD subjects and AD patients [275].

Another brain area that undergoes neurodegeneration in $\mathrm{AD}$ and might be important for circadian rhythm disturbance is the cholinergic basal forebrain. Cells of the nucleus basalis project to the $\mathrm{SCN}$, and cholinergic agents act in the SCN to modulate circadian rhythms [265]. An AD mouse model study has reported alterations in non-rapid eye movement sleep that could be due to alterations in cholinergic transmission [276], but clinical studies concerning the role of cholinergic depletion in circadian disturbance in $\mathrm{AD}$ are still lacking.

Sleep disturbance has been associated with vascular pathology in studies examining the incidence and severity of NPS [277-279]. Accordingly, increased white matter hyperintensities, reflecting vascular pathology of the white matter, which may be of $A \beta$-related origin, have been association with sleep disturbances in AD [279].

Of interest is the fact that rapid eye movement sleep behavior disorder, in which acting out of dream behavior is associated with preservation of body tone, is more common in synucleinopathies than in tauopathies, to the extent that some suggest that its presence may be a diagnostic feature [280].

\section{CONCLUSION}

A large body of evidence, of which only a sample set of studies were discussed in this review, clearly indicates that NPS in AD are associated with neurodegeneration affecting specific neural pathways, networks and circuits and that they are based on the interplay of neuropathological and neurochemical factors in the pathogenesis of AD. It is therefore well established that in the vast majority of cases, NPS are fundamental expressions of the underlying neurodegenerative brain disease and not simply reflect the patients' secondary response to his illness. Nevertheless, further refinement of the nosology of NPS is required since we are only beginning to understand the underlying pathophysiology. In addition, it is important to take into consideration that interpretation and comparison of biological NPS-related studies can be restricted by relatively small sample sizes (e.g. numbers of patients or brain regions included), variations in study design or measurement of included parameters. Neuropathological studies, moreover, include a majority of end-stage patient samples, which may not correctly represent the pathophysiological environment responsible for particular NPS that may already be present in an early stage, or even prior to AD diagnosis. The burdensome nature and prevalent occurrence of NPS, in combination with the fact that effective and safe treatment options are still lacking, provide a strong incentive to continue neuropathological and neurochemical, as well as of course imaging and other relevant approaches to further improve our apprehension of the neurobiology of NPS.

\section{CONFLICT OF INTEREST}

The authors confirm that this article content has no conflict of interest.

\section{ACKNOWLEDGEMENTS}

The work of all included authors was supported by the Research Foundation-Flanders (FWO), Interuniversity Poles of Attraction (IAP Network P7/16) of the Belgian Federal Science Policy Office, Methusalem excellence grant of the Flemish Government, agreement between Institute BornBunge and University of Antwerp, the Medical Research Foundation Antwerp, the Thomas Riellaerts research fund, Neurosearch Antwerp, and the Alzheimer Research Center of the University Medical Center Groningen (UMCG). A.D.D. was granted a $\mathrm{PhD}$ fellowship of the Research School of Behavioural and Cognitive Neurosciences of the UMCG.

All authors have contributed substantially to the design and writing of the review, as well as inclusion and interpretation of included research. 


\section{REFERENCES}

[1] Graham NL, Emery T, Hodges JR. Distinctive cognitive profiles in Alzheimer's disease and subcortical vascular dementia. J Neurol Neurosurg Psychiatry 75: 61-71 (2004).

[2] Geda YE, Schneider LS, Gitlin LN, Miller DS, Smith GS, Bell J, et al. Neuropsychiatric symptoms in Alzheimer's disease: past progress and anticipation of the future. Alzheimers Dement 9: 602-8 (2013).

[3] Reisberg B, Borenstein J, Salob SP, Ferris SH, Franssen E, Georgotas A. Behavioral symptoms in Alzheimer's disease: Phenomenology and treatment. J Clin Psychiatry 48: 9-15 (1987).

[4] Cummings JL, Mega M, Gray K, Rosenberg-Thompson S, Carusi DA, Gornbein J. The Neuropsychiatric Inventory: comprehensive assessment of psychopathology in dementia. Neurology 44: 230814 (1994).

[5] Mega MS, Cummings JL, Fiorello T, Gornbein J. The spectrum of behavioral changes in Alzheimer's disease. Neurology 46: 130-5 (1996).

[6] Cummings JL. The Neuropsychiatric Inventory: assessing psychopathology in dementia patients. Neurology 48: S10-6 (1997).

[7] Lyketsos CG, Carrillo MC, Ryan MJ, Khachaturian AS, Trzepacz $\mathrm{P}$, Amatniek J, et al. Neuropsychiatric symptoms in Alzheimer's disease. Alzheimers Dement 7: 532-9 (2011).

[8] Finkel SI, Costa e Silva J, Cohen G, Miller S, Sartorius N. Behavioral and psychological signs and symptoms of dementia: a consensus statement on current knowledge and implications for research and treatment. Int Psychogeriatr 8: 497-500 (1996).

[9] Lyketsos CG, Lopez O, Jones B, Fitzpatrick AL, Breitner J, DeKosky S. Prevalence of neuropsychiatric symptoms in dementia and mild cognitive impairment: results from the cardiovascular health study. JAMA 288: 1475-83 (2002).

[10] Okura T, Plassman BL, Steffens DC, Llewellyn DJ, Potter GG, Langa KM. Neuropsychiatric symptoms and the risk of institutionalization and death: the aging, demographics, and memory study. J Am Geriatr Soc 59: 473-81 (2011).

[11] González-Salvador MT, Arango C, Lyketsos CG, Barba AC. The stress and psychological morbidity of the Alzheimer patient caregiver. Int J Geriatr Psychiatry 14: 701-10 (1999).

[12] Emanuel JE, Lopez OL, Houck PR, Becker JT, Weamer EA, Demichele-Sweet MA, et al. Trajectory of cognitive decline as a predictor of psychosis in early Alzheimer disease in the cardiovascular health study. Am J Geriatr Psychiatry 19: 160-8 (2011).

[13] Douglas A, Letts L, Richardson J. A systematic review of accidental injury from fire, wandering and medication self-administration errors for older adults with and without dementia. Arch Gerontol Geriatr 52: e1-10 (2011).

[14] Herrmann N, Lanctôt KL, Sambrook R, Lesnikova N, Hébert R, McCracken $\mathrm{P}$, et al. The contribution of neuropsychiatric symptoms to the cost of dementia care. Int J Geriatr Psychiatry 21: 972-6 (2006).

[15] American Psychiatric Association. DSM-V: Diagnostic and Statistical Manual of Mental Disorders, 5th ed. Washington, DC: American Psychiatric Association 2013.

[16] Gauthier S, Cummings J, Ballard C, Brodaty H, Grossberg G, Robert $\mathrm{P}$, et al. Management of behavioral problems in Alzheimer's disease. Int Psychogeriatr 22: 346-72 (2010).

[17] Van Dam D, De Deyn PP. Drug discovery in dementia: the role of rodent models. Nat Rev Drug Discov 5: 956-70 (2006).

[18] Van Dam D, De Deyn PP. Animal models in the drug discovery pipeline for Alzheimer's disease. Br J Pharmacol 164: 1285-300 (2011).

[19] Lansbury PT Jr. In pursuit of the molecular structure of amyloid plaque: new technology provides unexpected and critical information. Biochemistry 31: 6865-70 (1992).

[20] Pearson HA, Peers C. Physiological roles for amyloid beta peptides. J Physiol 575: 5-10 (2006).

[21] Parihar MS, Brewer GJ. Amyloid-beta as a modulator of synaptic plasticity. J Alzheimers Dis 22: 741-63 (2010).

[22] Harper JD, Wong SS, Lieber CM, Lansbury PT. Observation of metastable Abeta amyloid protofibrils by atomic force microscopy. Chem Biol 4: 119-25 (1997).

[23] Lambert MP, Barlow AK, Chromy BA, Edwards C, Freed R, Liosatos M, et al. Diffusible, nonfibrillar ligands derived from Abeta142 are potent central nervous system neurotoxins. Proc Natl Acad Sci USA 95: 6448-53 (1998).
[24] Roher AE, Lowenson JD, Clarke S, Wolkow C, Wang R, Cotter $\mathrm{RJ}$, et al. Structural alterations in the peptide backbone of betaamyloid core protein may account for its deposition and stability in Alzheimer's disease. J Biol Chem 268: 3072-83 (1993).

[25] Iwatsubo T, Odaka A, Suzuki N, Mizusawa H, Nukina N, Ihara Y. Visualization of A beta 42(43) and A beta 40 in senile plaques with end-specific A beta monoclonals: evidence that an initially deposited species is A beta 42(43). Neuron 13: 45-53 (1994).

[26] Serrano-Pozo A, Frosch MP, Masliah E, Hyman BT. Neuropathological alterations in Alzheimer disease. Cold Spring Harb Perspect Med 1: a006189 (2011).

[27] Selkoe DJ. Alzheimer's disease. Cold Spring Harb Perspect Biol 3: a004457 (2011).

[28] Cruz L, Urbanc B, Buldyrev SV, Christie R, Gomez-Isla T, Havlin $\mathrm{S}$, et al. Aggregation and disaggregation of senile plaques in Alzheimer disease. Proc Natl Acad Sci USA 94: 7612-6 (1997).

[29] Thal DR, Walter J, Saido TC, Fandrich M. Neuropathology and biochemistry of Abeta and its aggregates in Alzheimer's disease. Acta Neuropathol 129: 167-82 (2015).

[30] Lacor PN, Buniel MC, Furlow PW, Clemente AS, Velasco PT, Wood $\mathrm{M}$, et al. $\mathrm{A} \beta$ oligomer-induced aberrations in synapse composition, shape, and density provide a molecular basis for loss of connectivity in Alzheimer's disease. J Neurosci 27: 796-807 (2007).

[31] Goate A, Chartier-Harlin MC, Mullan M, Brown J, Crawford F, Fidani L, et al. Segregation of a missense mutation in the amyloid precursor protein gene with familial Alzheimer's disease. Nature 349: 704-6 (1991).

[32] Tandon A, Rogaeva E, Mullan M, St George-Hyslop PH. Molecular genetics of Alzheimer's disease: the role of beta-amyloid and the presenilins. Curr Opin Neurol 13: 377-84 (2000).

[33] Vilatela MEA, Lopez-Lopez M, Yeseas-Gomez P. Genetics of Alzheimer's Disease. Arch Med Res 43: 622-31 (2012).

[34] Blennow K, de Leon MJ, Zetterberg H. Alzheimer's disease. Lancet 368: 387-403 (2006).

[35] Hardy J, Selkoe DJ. The amyloid hypothesis of Alzheimer's disease: progress and problems on the road to therapeutics. Science 297: 353-6 (2002).

[36] Teipel SJ, Hampel H. Neuroanatomy of Down syndrome in vivo: a model of preclinical Alzheimer's disease. Behav Genet 36: 405-415 (2006).

[37] Zigman WB, Lott IT. Alzheimer's Disease in Down Syndrome: Neurobiology and Risk. Ment Retard Dev Disabil Res Rev 13: 23746 (2007).

[38] Zigman WB. Atypical aging in down syndrome. Dev Disabil Res Rev 18: 51-67 (2013).

[39] Wiseman FK, Al-Janabi T, Hardy J, Karmiloff-Smith A, Nizetic D, Tybulewicz VL, et al. A genetic cause of Alzheimer disease: mechanistic insights from Down syndrome. Nat Rev Neurosci 16(9): 564-74 (2015).

[40] Patterson C, Feightner JW, Garcia A, Hsiung GY, MacKnight C, Sadovnick AD. Diagnosis and treatment of dementia: 1. Risk assessment and primary prevention of Alzheimer disease. CMAJ 178: 548-56 (2008).

[41] Holtzman DM, Bales KR, Tenkova T, Fagan AM, Parsadanian M, Sartorius LJ, et al. Apolipoprotein E isoform-dependent amyloid deposition and neuritic degeneration in a mouse model of Alzheimer's disease. Proc Natl Acad Sci USA 97: 2892-7 (2000).

[42] Jack CR Jr, Knopman DS, Jagust WJ, Shaw LM, Aisen PS, Weiner MW, et al. Hypothetical model of dynamic biomarkers of the Alzheimer's pathological cascade. Lancet Neurol 9: 119-28 (2010). Borchelt DR, Thinakaran G, Eckman CB, Lee MK, Davenport F, Ratovitsky T, et al. Familial Alzheimer's disease-linked presenilin 1 variants elevate Abeta1-42/1-40 ratio in vitro and in vivo. Neuron 17: 1005-13 (1996).

[44] Duff K, Eckman C, Zehr C, Yu X, Prada CM, Perez-tur J, et al. Increased amyloid-beta42(43) in brains of mice expressing mutant presenilin 1. Nature 383: 710-3 (1996).

[45] Hutton M, Lendon CL, Rizzu P, Baker M, Froelich S, Houlden H, et al. Association of missense and 5'-splice-site mutations in tau with the inherited dementia FTDP-17. Nature 393: 702-5 (1998).

[46] Lewis J, Dickson DW, Lin WL, Chisholm L, Corral A, Jones G, et al. Enhanced neurofibrillary degeneration in transgenic mice expressing mutant tau and APP. Science 293: 1487-91 (2001). 
[47] Oliver C, Crayton L, Holland A, Hall S, Bradbury J. A four year prospective study of age-related cognitive change in adults with Down's syndrome. Psychol Med 28:1365-77 (1998).

[48] Arriagada PV, Growdon JH, Hedley-Whyte ET, Hyman BT. Neurofibrillary tangles but not senile plaques parallel duration and severity of Alzheimer's disease. Neurology 42: 631-9 (1992).

[49] Karran E, Mercken M, De Strooper B. The amyloid cascade hypothesis for Alzheimer's disease: an appraisal for the development of therapeutics. Nat Rev Drug Discov 10: 698-712 (2011).

[50] Wisniewski KE, Wisniewski HM, Wen GY. ccurrence of neuropathological changes and dementia of Alzheimer's disease in Down's syndrome. Ann Neurol 17: 278-82 (1985).

[51] Lott IT, Dierssen M. Cognitive deficits and associated neurological complications in individuals with Down's syndrome. Lancet Neurol 9: 623-33 (2010).

[52] Jucker M, Walker LC. Pathogenic protein seeding in Alzheimer disease and other neurodegenerative disorders. Ann Neurol 70: 532-40 (2011).

[53] Arnold SE, Hyman BT, Flory J, Damasio AR, Van Hoesen GW. The topographical and neuroanatomical distribution of neurofibrillary tangles and neuritic plaques in the cerebral cortex of patients with Alzheimer's disease. Cereb Cortex 1: 103-16 (1991).

[54] Braak H, Braak E. Neuropathological stageing of Alzheimerrelated changes. Acta Neuropathol 82: 239-59 (1991).

[55] Thal DR, Rüb U, Orantes M, Braak H. Phases of A $\beta$ deposition in the human brainn and its relevance for the development of AD. Neurology 58: 1791-800 (2002).

[56] Montine TJ, Phelps CH, Beach TG, Bigio EH, Cairns NJ, Dickson DW, et al. National Institute on Aging-Alzheimer's Association guidelines for the neuropathologic assessment of Alzheimer's disease: a practical approach. Acta Neuropathol 123: 1-11 (2012).

[57] Love S, Saitoh T, Quijada S, Cole GM, Terry RD. Alz-50, ubiquitin and tau immunoreactivity of neurofibrillary tangles, Pick bodies and Lewy bodies. J Neuropath Exp Neurol 47: 393-405 (1988).

[58] Perl DP. Neuropathology of Alzheimer's disease. Mt Sinai J Med New 77: 32-42 (2010).

[59] Mesulam MM, Asuncion MM. Cholinesterases within neurofibrillary tangles related to age and Alzheimer's disease. Ann Neurol 22: 223-8 (1987).

[60] Iqbal K, Alonso Adel C, Chen S, Chohan MO, El-Akkad E, et al. Tau pathology in Alzheimer disease and other tauopathies. Biochim Biophys Acta 1739: 198-210 (2005).

[61] Braak E, Griffing K, Arai K, Bohl J, Bratzke H, Braak H. Neuropathology of Alzheimer's disease: what is new since A. Alzheimer? Eur Arch Psychiatry Clin Neurosci 249: 14-22 (1999).

[62] Braak E, Braak H, Mandelkow EM. A sequence of cytoskeleton changes related to the formation of neurofibrillary tangles and neuropil threads. Acta Neuropathol 87: 554-67 (1994).

[63] Villemagne VL, Okamura N. In vivo tau imaging: obstacles and progress. Alzheimers Dement 10: S254-S64 (2014).

[64] Villemagne VL, Fodero-Tavoletti MT, Masters CL, Rowe CC. Tau imaging: early progress and future directions. Lancet Neurol 14: 114-24 (2015).

[65] Soto C. Unfolding the role of protein misfolding in neurodegenerative diseases. Nat Rev Neurosci 4: 49-60 (2003).

[66] Hamilton RL. Lewy bodies in Alzheimer's disease: a neuropathological review of 145 cases using alpha-synuclein immunohistochemistry. Brain Pathol 10: 378-84 (2000).

[67] Hansen L, Salmon D, Galasko D, Masliah E, Katzman R, DeTeresa $\mathrm{R}$, et al. The Lewy body variant of Alzheimer's disease: a clinical and pathologic entity. Neurology 40: 1-8 (1990).

[68] Olichney JM, Galasko D, Salmon DP, Hofstetter CR, Hansen LA, Katzman R, et al. Cognitive decline is faster in Lewy body variant than in Alzheimer's disease. Neurology 51: 351-7 (1998).

[69] Marsh SE, Blurton-Jones M. Examining the mechanisms that link b-amyloid and a-synuclein pathologies. Alzheimers Res Ther 4: 11 (2012).

[70] Resende R, Marques SC, Ferreiro E, Simões I, Oliveira CR, Pereira CM. Effect of $\alpha$-synuclein on amyloid $\beta$-induced toxicity: relevance to Lewy body variant of Alzheimer disease. Neurochem Res 38: 797-806 (2013)

[71] Cummings CJ, Zoghbi HY. Fourteen and counting: unraveling trinucleotide repeat diseases. Hum Mol Genet 9: 909-16 (2000).
[72] Fujigasaki H, Martin JJ, De Deyn PP, Camuzat A, Deffond D, Stevanin $\mathrm{G}$, et al. CAG repeat expansion in the TATA box-binding protein gene causes autosomal dominant cerebellar ataxia. Brain 124: 1939-47 (2001).

[73] Reid SJ, van Roon-Mom WM, Wood PC, Rees MI, Owen MJ, Faull RL, et al. TBP, a polyglutamine tract containing protein, accumulates in Alzheimer's disease. Brain Res Mol Brain Res 125: 120-8 (2004).

[74] Bruijn LI, Houseweart MK, Kato S, Anderson KL, Anderson SD, Ohama E, et al. Aggregation and motor neuron toxicity of an ALSlinked SOD1 mutant independent from wild-type SOD1. Science 281: 1851-4 (1998).

[75] Choi J, Rees HD, Weintraub ST, Levey AI, Chin LS, Li L. Oxidative modifications and aggregation of $\mathrm{Cu}, \mathrm{Zn}$-superoxide dismutase associated with Alzheimer and Parkinson diseases. J Biol Chem 280: 11648-55 (2005)

[76] Atkin G, Paulson H. Ubiquitin pathways in neurodegenerative disease. Front Mol Neurosci 7: 63 (2014).

[77] Perry G, Friedman R, Shaw G, Chau V. Ubiquitin is detected in neurofibrillary tangles and senile plaque neurites of Alzheimer disease brains. Proc Natl Acad Sci USA 84: 3033-36 (1987).

[78] Upadhya SC, Hegde AN. Role of the ubiquitin proteasome system in Alzheimer's disease. BMC Biochem 8: S12 (2007).

[79] Riederer BM, Leuba G, Vernay A, Riederer IM. The role of the ubiquitin proteasome system in Alzheimer's disease. Exp Biol Med (Maywood) 236: 268-76 (2011).

[80] Neumann M, Sampathu DM, Kwong LK, Truax AC, Micsenyi $\mathrm{MC}$, Chou TT, et al. Ubiquitinated TDP-43 in frontotemporal lobar degeneration and amyotrophic lateral sclerosis. Science 314: 130-3 (2006).

[81] Josephs KA, Whitwell JL, Knopman DS, Hu WT, Stroh DA, Baker $\mathrm{M}$, et al. Abnormal TDP-43 immunoreactivity in AD modifies clinicopathologic and radiologic phenotype. Neurology 70: 1850-7 (2008).

[82] Uryu K, Nakashima-Yasuda H, Forman MS, Kwong LK, Clark $\mathrm{CM}$, Grossman M, et al. Concomitant TAR-DNA-binding protein 43 pathology is present in Alzheimer disease and corticobasal degeneration but not in other tauopathies. J Neuropathol Exp Neurol 67: 555-64 (2008)

[83] Kadokura A, Yamazaki T, Lemere CA, Takatama M, Okamoto K. Regional distribution of TDP-43 inclusions in Alzheimer disease (AD) brains: their relation to $\mathrm{AD}$ common pathology. Neuropathology 29: 566-73 (2009)

[84] Herman AM, Khandelwal PJ, Stanczyk BB, Rebeck GW, Moussa CE. $\beta$-amyloid triggers ALS-associated TDP-43 pathology in AD models. Brain Res 1386: 191-9 (2011).

[85] Akiyama H, Barger S, Barnum S, Bradt B, Bauer J, Cole GM, et al. Inflammation and Alzheimer's disease. Neurobiol Aging 21: 383421 (2000).

[86] Hensley K. Neuroinflammation in Alzheimer's disease: mechanisms, pathologic consequences, and potential for therapeutic manipulation. J Alzheimers Dis 21: 1-14 (2010).

[87] Heneka MT, Carson MJ, El Khoury J, Landreth GE, Brosseron F, Feinstein DL, et al. Neuroinflammation in Alzheimer's disease. Lancet Neurol 14: 388-405 (2015).

[88] Kettenmann H, Hanisch UK, Noda M, Verkhratsky A. Physiology of microglia. Physiol Rev 91: 461-553 (2011).

[89] Reed-Geaghan EG, Savage JC, Hise AG, Landreth GE. CD14 and Toll-like receptors 2 and 4 are required for fibrillar $A \beta$-stimulated microglial activation. J Neurosci 29: 11982-92 (2009).

[90] Hong S, Ostaszewski BL, Yang T, O'Malley TT, Jin M, Yanagisawa $\mathrm{K}$, et al. Soluble A $\beta$ oligomers are rapidly sequestered from brain ISF in vivo and bind GM1 ganglioside on cellular membranes. Neuron 82: 308-19 (2014).

[91] Beauquis J, Vinuesa A, Pomilio C, Pavía P, Galván V, Saravia F. Neuronal and glial alterations, increased anxiety, and cognitive impairment before hippocampal amyloid deposition in PDAPP mice, model of Alzheimer's disease. Hippocampus 24: 257-69 (2014).

[92] Mrak RE, Sheng JG, Griffin WS. Glial cytokines in Alzheimer's disease: review and pathogenic implications. Hum Pathol 26: 81623 (1995).

[93] Akiyama H, Kawamata T, Yamada T, Tooyama I, Ishii T, McGeer PL. Expression of intercellular adhesion molecule (ICAM)-1 by a subset of astrocytes in Alzheimer disease and some other degenerative neurological disorders. Acta Neuropathol (Berlin) 85: 628-34 (1993). 
[94] Savarin-Vuaillat C, Ransohoff RM. Chemokines and chemokine receptors in neurological disease: raise, retain, or reduce? Neurotherapeutics 4: 590-601 (2007).

[95] Rohn TT. The role of caspases in Alzheimer's disease; potential novel therapeutic opportunities. Apoptosis 15: 1403-9 (2010).

[96] Montine TJ, Sidell KR, Crews BC, Markesbery WR, Marnett LJ, Roberts LJ 2nd, et al. Elevated CSF prostaglandin E2 levels in patients with probable AD. Neurology 53: 1495-98 (1999).

[97] Strohmeyer R, Ramirez M, Cole GJ, Mueller K, Rogers J. Association of factor $\mathrm{H}$ of the alternative pathway of complement with agrin and complement receptor 3 in the Alzheimer's disease brain. J Neuroimmunol 131: 135-46 (2002).

[98] Vodovotz Y, Lucia MS, Flanders KC, Chesler L, Xie QW, Smith $\mathrm{TW}$, et al. Inducible nitric oxide synthase in tangle-bearing neurons of patients with Alzheimer's disease. J Exp Med 184: 1425-33 (1996).

[99] Iadecola C. Neurovascular regulation in the normal brain and in Alzheimer's disease. Nat Rev Neurosci 5: 347-60 (2004).

[100] Sofroniew MV, Vinters HV. Astrocytes: biology and pathology. Acta Neuropathol 119: 7-35 (2010).

[101] Najjar S, Pearlman DM, Alper K, Najjar A, Devinsky O. Neuroinflammation and psychiatric illness. J Neuroinflamm 10: 43 (2013).

[102] Itagaki S, McGeer PL, Akiyama H, Zhu S, Selkoe D. Relationship of microglia and astrocytes to amyloid deposits of Alzheimer's disease. J Neuroimmunol 24: 173-82 (1989).

[103] Pike CJ, Cummings BJ, Cotman CW. Early association of reactive astrocytes with senile plaques in Alzheimer's disease. Exp Neurol 132: 172-9 (1995).

[104] Serrano-Pozo A, Mielke ML, Gómez-Isla T, Betensky RA, Growdon JH, Frosch MP, et al. Reactive glia not only associates with plaques but also parallels tangles in Alzheimer's disease. Am J Pathol 179: 1373-84 (2011).

[105] Bozyczko-Coyne D, O'Kane TM, Wu ZL, Dobrzanski P, Murthy S, Vaught JL, Scott RW. CEP-1347/KT-7515, an inhibitor of SAPK/JNK pathway activation, promotes survival and blocks multiple events associated with Abeta-induced cortical neuron apoptosis. J Neurochem 77: 849-63 (2001).

[106] Morishima Y, Gotoh Y, Zieg J, Barrett T, Takano H, Flavell R, et al. Beta-amyloid induces neuronal apoptosis via a mechanism that involves the c-Jun $\mathrm{N}$-terminal kinase pathway and the induction of Fas ligand. J Neurosci 21: 7551-60 (2001).

[107] Canevari L, Abramov A, Duchen M. Toxicity of amyloid beta peptide: tales of calcium, mitochondria, and oxidative stress. Neurochem Res 29: 637-50 (2004).

[108] Donev R, Kolev M, Millet B, Thome J. Neuronal death in Alzheimer's disease and therapeutic opportunities. J Cell Mol Med 13: 4329-48 (2009).

[109] Morishima-Kawashima M, Oshima N, Ogata H, Yamaguchi H, Yoshimura M, Sugihara S, et al. Effect of apolipoprotein E allele epsilon 4 on the initial phase of amyloid beta-protein accumulation in the human brain. Am J Pathol 157: 2093-9 (2000).

[110] Lue LF, Kuo YM, Roher AE, Brachova L, Shen Y, Sue L, et al. Soluble amyloid beta peptide concentration as a predictor of synaptic change in Alzheimer's disease. Am J Pathol 155: 853-62 (1999).

[111] Mucke L, Masliah E, Yu GQ, Mallory M, Rockenstein EM, Tatsuno G, et al. High-level neuronal expression of abeta 1-42 in wild-type human amyloid protein precursor transgenic mice: synaptotoxicity without plaque formation. J Neurosci 20: 4050-8 (2000).

[112] DeKosky ST, Scheff SW. Synapse loss in frontal cortex biopsies in Alzheimer's disease: correlation with cognitive severity. Ann Neurol 27: 457-64 (1990).

[113] Scheff SW, DeKosky ST, Price DA. Quantative assessment of cortical synaptic density in Alzheimer's disease. Neurobiol Aging 11: 29-37 (1990).

[114] Masliah E, Terry R. The role of synaptic pathology in the mechanisms of dementia in Alzheimer's disease. Clin Neurosci 1: 192-8 (1994).

[115] Gonatas NK. Neocortical synapses in a presenile dementia. J Neuropath Exp Neurol 26: 150-1 (1967).

[116] Baloyannis SJ. Dendritic pathology in Alzheimer's disease. J Neurol Sci 283: 153-7 (2009).

[117] Falke E, Nissanov J, Mitchel TW, Bennet DA, Trojanowski JO, Arnold SE. Subiculum dendritic arborization in Alzheimer's disease correlates with neurofibrillary tangle density. Am J Pathol 163: 1615-31 (2006).

[118] Baloyannis SJ, Costa V, Mauroudis I, Psaroulis D, Manolides SL, Manolides LS. Dendritic and spinal pathology in the acoustic cortex in Alzheimer's disease: morphological and morphometric estimation by Golgi technique and electron microscopy. Acta Otolaryngol 127: 351-4 (1953).

[119] Paula-Barbosa MM, Cardoso RM, Guimaraes ML, Cruz C. Dendritic degeneration and regrowth in the cerebral cortex of patients with Alzheimer's disease. J Neurol Sci 45: 129-34 (1980).

[120] Baloyannis SJ, Manolides SL, Manolides LS. Dendritic and spinal pathology in the acoustic cortex in Alzheimer's disease: morphological estimation in Golgi technique and electron microscopy. Acta Otolaryngol 131: 610-2 (2011).

[121] Mavroudis IA, Fotiou DF, Manani MG, Njaou SN, Frangou D, Costa VG, et al. Dendritic pathology and spinal loss in the visual cortex in Alzheimer's disease: a Golgi study in pathology. Int $\mathrm{J}$ Neurosci 121: 347-54 (2011).

[122] Kummer MP, Heneka MT. Truncated and modified amyloid-beta species. Alzheimers Res Ther 6: 28 (2014).

[123] Alexander GE, Crutcher MD, DeLong MR. Basal gangliathalamocortical circuits: parallel substrates for motor, oculomotor, "prefrontal" and "limbic" functions. Prog Brain Res 85: 119-46 (1990).

[124] Cummings JL. Frontal-subcortical circuits and human behavior. Arch Neurol 50: 873-80 (1993).

[125] Mesulam MM. From sensation to cognition. Brain 121: 1013-52 (1998).

[126] Trillo L, Das D, Hsieh W, Medina B, Moghadam S, Lin B, et al. Ascending monoaminergic systems alterations in Alzheimer's disease. Translating basic science into clinical care. Neurosci Biobehav Rev 37: 1363-79 (2013).

[127] Geschwind N, Kaplan E. A human cerebral deconnection syndrome. A preliminary report. Neurology 12: 675-85 (1962).

[128] Catani M, Dell'acqua F, Thiebaut de Schotten M. A revised limbic system model for memory, emotion and behavior. Neurosci Biobehav Rev 37: 1724-37 (2013).

[129] Fuxe K, Dahlstrom A, Hoistad M, Marcellino D, Jansson A, Rivera A, et al. From the Golgi-Cajal mapping to the transmitter-based characterization of the neuronal networks leading to two modes of brain communication: wiring and volume transmission. Brain Res Rev 55: 17-54 (2007).

[130] Sluimer JD, van der Flier WM, Karas GB, Fox NC, Scheltens P, Barkhof $\mathrm{F}$, et al. Wholebrain atrophy rate and cognitive decline: longitudinal MR study of memory clinic patients. Radiology 248 : 590-8 (2008).

[131] Chan D, Janssen JC, Whitwell JL, Watt HC, Jenkins R, Frost C, et al. Change in rates of cerebral atrophy over time in early-onset Alzheimer's disease: longitudinal MRI study. Lancet 362: 1121-2 (2003).

[132] Thompson PM, Hayashi KM, de Zubicaray G, Janke AL, Rose SE, Semple J, et al. Dynamics of gray matter loss in Alzheimer's disease. J Neurosci 23: 994-1005 (2003).

[133] Ridha BH, Barnes J, Bartlett JW, Godbolt A, Pepple T, Rossor MN, et al. Tracking atrophy progression in familial Alzheimer's disease: a serial MRI study. Lancet Neurol 5: 828-34 (2006).

[134] Singh V, Chertkow H, Lerch JP, Evans AC, Dorr AE, Kabani NJ. Spatial patterns of cortical thinning in mild cognitive impairment and Alzheimer's disease. Brain 129: 2885-93 (2006).

[135] McDonald CR, McEvoy LK, Gharapetian L, Fennema-Notestine C, Hagler DJ Jr, Holland D, et al. for the Alzheimer's Disease Neuroimaging Initiative. Regional rates of neocortical atrophy from normal aging to early Alzheimer disease. Neurology 73: 457-65 (2009).

[136] Lopez OL, Zivkovic S, Smith G, Becker JT, Meltzer CC, DeKosky ST. Psychiatric symptoms associated with cortical-subcortical dysfunction in Alzheimer's disease. J Neuropsychiatr Clin Neurosci 13: 56-60 (2001).

[137] Ball SL, Holland AJ, Watson PC, Huppert FA. Theoretical exploration of the neural bases of behavioural disinhibition, apathy and executive dysfunction in preclinical Alzheimer's disease in people with Down's syndrome: potential involvement of multiple frontalsubcortical neuronal circuits. J Intellect Disabil Res 54: 320-36 (2010).

[138] Peavy GM, Salmon DP, Edland SD, Tam S, Hansen LA, Masliah $\mathrm{E}$, et al. Neuropsychiatric features of frontal lobe dysfunction in 
autopsy-confirmed patients with lewy bodies and "pure" Alzheimer disease. Am J Geriatr Psychiatry 21: 509-19 (2013).

[139] Minoshima S, Giordani B, Berent S, Frey KA, Foster NL, Kuhl DE. Metabolic reduction in the posterior cingulate cortex in very early Alzheimer's disease. Ann Neurol 42: 85-94 (1997).

[140] Buckner RL, Snyder AZ, Shannon BJ, LaRossa G, Sachs R, Fotenos AF, et al. Molecular, structural, and functional characterization of Alzheimer's disease: evidence for a relationship between default activity, amyloid, and memory. J Neurosci 25: 7709-17 (2005)

[141] Broyd SJ, Demanuele C, Debener S, Helps SK, James CJ, SonugaBarke EJ. Default-mode brain dysfunction in mental disorders: a systematic review. Neurosci Biobehav Rev 33: 279-96 (2009).

[142] Zhou J, Greicius MD, Gennatas ED, Growdon ME, Jang JY, Rabinovici GD, et al. Divergent network connectivity changes in behavioural variant frontotemporal dementia and Alzheimer's disease. Brain 133: 1352-67 (2010).

[143] Oh H, Mormino EC, Madison C, Hayenga A, Smiljic A, Jagust WJ. $\beta$-Amyloid affects frontal and posterior brain networks in normal aging. Neuroimage 54: 1887-95 (2011)

[144] Francis PT, Palmer AM, Snape M, Wilcock GK. The cholinergic hypothesis of Alzheimer's disease: a review of progress. J Neurol Neurosurg Psychiatry 66: 137-47 (1999).

[145] Wenk GL. Neuropathologic changes in Alzheimer's disease. J Clin Psychiatry 64: 7-10 (2003).

[146] Parvizi J, van Hoesen GW, Damasio A. The selective vulnerability of brainstem nuclei to Alzheimer's disease. Ann Neurol 49: 53-66 (2001).

[147] Starkstein SE, Mizrahi R. Depression in Alzheimer's disease. Expert Rev Neurother 6: 887-95 (2006).

[148] Van der Mussele S, Bekelaar K, Le Bastard N, Vermeiren Y, Saerens J, Somers $\mathrm{N}$, et al. Prevalence and associated behavioral symptoms of depression in mild cognitive impairment and dementia due to Alzheimer's disease. Int J Geriatr Psychiatry 28: 947-58 (2013).

[149] Kessing LV. Depression and the risk for dementia. Curr Opin Psychiatry 25: 457-61 (2012)

[150] Ballmaier M, Sowell ER, Thompson PM, Kumar A, Narr KL, Lavretsky $\mathrm{H}$, et al. Mapping brain size and cortical gray matter changes in elderly depression. Biol Psychiatry 55: 382-9 (2004).

[151] Campbell S, Marriott M, Nahmias C, MacQueen GM. Lower hippocampal volume in patients suffering from depression: a metaanalysis. Am J Psychiatry 161: 598-607 (2004).

[152] Egger K, Schocke M, Weiss E, Auffinger S, Esterhammer R, Goebel G, et al. Pattern of brain atrophy in elderly patients with depression revealed by voxel-based morphometry. Psychiatr Res 164: 237-44 (2008).

[153] Lee GJ, Lu PH, Hua X, Lee S, Wu S, Nguyen K, et al. Depressive symptoms in mild cognitive impairment predict greater atrophy in Alzheimer's disease-related regions. Biol Psychiatry 71: 814-21 (2012).

[154] Zahodne LB, Gongvatana A, Cohen RA, Ott BR, Tremont G, for the Alzheimer's Disease Neuroimaging Initiative. Are apathy and depression independently associated with longitudinal trajectories of cortical atrophy in mild cognitive impairment? Am J Geriatr Psychiatry 21: 1098-106 (2013).

[155] Royall DR, Palmer RF. Alzheimer's disease pathology does not mediate the association between depressive symptoms and subsequent cognitive decline. Alzheimers Dement 9: 318-25 (2013).

[156] Royall DR, Palmer RF, Vidoni ED, Honea RA. The default mode network may be the key substrate of depressive symptom-related cognitive changes. J Alzheimers Dis 34: 547-59 (2013).

[157] Wu D, Yuan Y, Bai F, You J, Li L, Zhang Z. Abnormal functional connectivity of the default mode network in remitted late-onset depression. J Affect Disord 147: 277-87 (2013).

[158] Munro CE, Donovan NJ, Guercio BJ, Wigman SE, Schultz AP, Amariglio RE, et al. Neuropsychiatric Symptoms and Functional Connectivity in Mild Cognitive Impairment. J Alzheimers Dis 46: 727-35 (2015).

[159] Rapp MA, Schnaider-Beeri M, Grossman HT, Sano M, Perl DP, Purohit DP, et al. Increased hippocampal plaques and tangles in patients with Alzheimer disease with a lifetime history of major depression. Arch Gen Psychiatry 63: 161-7 (2006)

[160] Klatka LA, Louis ED, Schiffer RB. Psychiatric features in diffuse Lewy body disease: a clinicopathologic study using Alzheimer's disease and Parkinson's disease comparison groups. Neurology 47: 1148-52 (1996).

[161] Papka M, Rubio A, Schiffer RB, Cox C. Lewy body disease: can we diagnose it? J Neuropsychiatr Clin Neurosci 10: 405-12 (1998).

[162] Ballard C, Holmes C, McKeith I, Neill D, O’Brien J, Cairns N, et al. Psychiatric morbidity in dementia with Lewy bodies: a prospective clinical and neuropathological comparative study with Alzheimer's disease. Am J Psychiatry 156: 1039-45 (1999)

[163] Fritze F, Ehrt U, Hortobagyi I, Ballard C, Aarsland D. Depressive symptoms in Alzheimer's disease and Lewy body dementia: a oneyear follow-up study. Dement Geriatr Cogn Disord 32: 143-9 (2011).

[164] Lopez OL, Hamilton RL, Becker JT, Wisniewski S, Kaufer DI, DeKosky ST. Severity of cognitive impairment and the clinical diagnosis of AD with Lewy bodies. Neurology 54: 1780-7 (2000).

[165] Lopez OL, Becker JT, Sweet RA, Martin-Sanchez FJ, Hamilton RL. Lewy bodies in the amygdala increase risk for major depression in subjects with Alzheimer disease. Neurology 67: 660-5 (2006).

[166] Drevets WC. Neuroimaging abnormalities in the amygdala in mood disorders. Ann N Y Acad Sci 985: 420-44 (2003).

[167] Smith MC, Mallory M, Hansen LA, Ge N, Masliah E. Fragmentation of the neuronal cytoskeleton in the Lewy body variant of Alzheimer's disease. NeuroReport 6: 673-9 (1995).

[168] Uversky VN. Alpha-synuclein misfolding and neurodegenerative diseases. Curr Protein Pept Sci 9: 507-40 (2008).

[169] Chan-Palay V, Asan E. Alterations in catecholamine neurons of the locus coeruleus in senile dementia of the Alzheimer type and in Parkinson's disease with and without dementia and depression. J Comp Neurol 287: 373-92 (1989).

[170] Förstl H, Burns A, Luthert P, Cairns N, Lantos P, Levy R. Clinical and neuropathological correlates of depression in Alzheimer's disease. Psychol Med 22: 877-84 (1992).

[171] Zubenko GS, Moossy J, Kopp U. Neurochemical correlates of major depression in primary dementia. Arch Neurol 47: 209-14 (1990).

[172] Vermeiren Y, Van Dam D, Aerts T, Engelborghs S, De Deyn PP. Monoaminergic neurotransmitter alterations in postmortem brain regions of depressed and aggressive patients with Alzheimer's disease. Neurobiol Aging 35: 2691-700 (2014)

[173] Vermeiren Y, Van Dam D, Aerts T, Engelborghs S, De Deyn PP. Brain region-specific monoaminergic correlates of neuropsychiatric symptoms in Alzheimer's disease. J Alzheimers Dis 41: 819-33 (2014).

[174] O'Halloran CJ, Kinsella GJ, Storey E. The cerebellum and neuropsychological functioning: A critical review. J Clin Exp Neuropsychol 34: 35-56 (2012).

[175] Goeb JL, Even C, Nicolas G, Gohier B, Dubas F, Garré JB. Psychiatric side effects of interferon-beta in multiple sclerosis. Eur Psychiatry 21: 186-93 (2006).

[176] O'Connor JC, André C, Wang Y, Lawson MA, Szegedi SS, Lestage $\mathrm{J}$, et al. Interferon-gamma and tumor necrosis factor-alpha mediate the upregulation of indoleamine 2,3-dioxygenase and the induction of depressive-like behavior in mice in response to bacillus Calmette-Guerin. J Neurosci 13: 4200-9 (2009).

[177] Dobos N, Korf J, Luiten PG, Eisel UL. Neuroinflammation in Alzheimer's disease and major depression. Biol Psychiatry 67: 5034 (2010).

[178] Naudé PJ, Nyakas C, Eiden LE, Ait-Ali D, van der Heide R, Engelborghs $\mathrm{S}$, et al. Lipocalin 2: novel component of proinflammatory signaling in Alzheimer's disease. FASEB J 26: 2811-23 (2012).

[179] Naudé PJ, Eisel UL, Comijs HC, Groenewold NA, De Deyn PP, Bosker FJ, et al. Neutrophil gelatinase-associated lipocalin: a novel inflammatory marker associated with late-life depression. J Psychosom Res 75: 444-50 (2013).

[180] Naudé PJ, den Boer JA, Comijs HC, Bosker FJ, Zuidersma M, Groenewold NA, et al. Sex-specific associations between Neutrophil Gelatinase-Associated Lipocalin (NGAL) and cognitive domains in late-life depression. Psychoneuroendocrinology 48: 16977 (2014)

[181] Naudé PJ, Dekker AD, Coppus AM, Vermeiren Y, Eisel UL, van Duijn CM, et al. Serum NGAL is Associated with Distinct Plasma Amyloid- $\beta$ Peptides According to the Clinical Diagnosis of Dementia in Down Syndrome. J Alzheimers Dis 45: 733-43 (2015). 
[182] Donnemiller E, Heilmann J, Wenning GK, Berger W, Decristoforo C, Moncayo R, et al. Brain perfusion scintigraphy with $99 \mathrm{mTc}-$ HMPAO or $99 \mathrm{mTc}-\mathrm{ECD}$ and 123I-beta-CIT single-photon emission tomography in dementia of the Alzheimer-type and diffuse Lewy body disease. Eur J Nucl Med 24: 320-5 (1997).

[183] Hirono N, Mori E, Ishii K, Ikejiri Y, Imamura T, Shimomura T, et al. Frontal lobe hypometabolism and depression in Alzheimer's disease. Neurology 50: 380-3 (1998).

[184] Levy-Cooperman N, Burhan AM, Rafi-Tari S, Kusano M, Ramirez J, Caldwell C, et al. Frontal lobe hypoperfusion and depressive symptoms in Alzheimer disease. J Psychiatr Neurosci 33: 218-26 (2008).

[185] Caroli A, Geroldi C, Nobili F, Barnden LR, Guerra UP, Bonetti M, et al. Functional compensation in incipient Alzheimer's disease. Neurobiol Aging 31: 387-97 (2010).

[186] Kataoka K, Hashimoto H, Kawabe J, Higashiyama S, Akiyama H, Shimada A, et al. Frontal hypoperfusion in depressed patients with dementia of Alzheimer type demonstrated on 3DSRT. Psychiatr Clin Neurosci 64: 293-8 (2010).

[187] Pedrosa R, Teixeira-Sousa V, Fonseca S, Bastos-Leite AJ. Earlyonset Alzheimer disease: the contribution of neuroimaging for the diagnosis. Psychiatr Res 182: 287-8 (2010).

[188] Starkstein SE, Mizrahi R, Capizzano AA, Acion L, Brockman S, Power BD. Neuroimaging correlates of apathy and depression in Alzheimer's disease. J Neuropsychiatr Clin Neurosci 21: 259-65 (2009).

[189] Hendricksen M, Thomas AJ, Ferrier IN, Ince P, O'Brien JT. Neuropathological study of the dorsal raphe nuclei in late-life depression and Alzheimer's disease with and without depression. Am J Psychiatry 161: 1096-102 (2004).

[190] Chen CP, Alder JT, Bowen DM, Esiri MM, McDonald B, Hope T, et al. Presynaptic serotonergic markers in community-acquired cases of Alzheimer's disease: correlations with depression and neuroleptic medication. J Neurochem 66: 1592-8 (1996).

[191] Ballard C, Johnson M, Piggott M, Perry R, O’Brien J, Rowan E, et al. A positive association between $5 \mathrm{HT}$ re-uptake binding sites and depression in dementia with Lewy bodies. J Affect Disord 69: 21923 (2002).

[192] Lai MK, Tsang SW, Esiri MM, Francis PT, Wong PT, Chen CP. Differential involvement of hippocampal serotonin1A receptors and re-uptake sites in non-cognitive behaviors of Alzheimer's disease. Psychopharmacology (Berl) 213: 431-9 (2011).

[193] Romano A, Pace L, Tempesta B, Lavecchia AM, Macheda T, Bedse G, et al. Depressive-like behavior is paired to monoaminergic alteration in a murine model of Alzheimer's disease. Int J Neuropsychopharmacol 18: pii: pyu020 (2014).

[194] Tagariello P, Girardi P, Amore M. Depression and apathy in dementia: same syndrome or different constructs? A critical review. Arch Gerontol Geriatry 49: 246-249 (2009).

[195] McPherson S, Fairbanks L, Tiken S, Cummings JL, Back-Madruga C. Apathy and executive function in Alzheimer's disease. J Int Neuropsychol Soc 8: 373-81 (2002).

[196] Nakaaki S, Murata Y, Sato J, Shinagawa Y, Hongo J, Tatsumi H. Association between apathy/depression and executive function in patients with Alzheimer's disease. Int Psychogeriatry 20: 964-75 (2008).

[197] Marin RS. Apathy: a neuropsychiatric syndrome. J Neuropsychiatry Clin Neurosci 3: 243-54 (1991).

[198] Levy ML, Cummings JL, Fairbanks LA, Masterman D, Miller BL, $\mathrm{Craig} \mathrm{AH}$, et al. Apathy is not depression. J Neuropsychiatr Clin Neurosci 10: 314-9 (1998).

[199] Andersson S, Krogstad JM, Finset A. Apathy and depressed mood in acquired brain damage: relationship to lesion localization and psychophysiological reactivity. Psychol Med 29: 447-56 (1999).

[200] Barnhart WJ, Makela EH, Latocha MJ. SSRI-induced apathy syndrome:a clinical review. J Psychiatr Pract 10: 196-9 (2004)

[201] Guimarães HC, Levy R, Teixeira AL, Beato RG, Caramelli P. Neurobiology of apathy in Alzheimer's disease. Arq Neuropsiquiatry 66: 436-43 (2008).

[202] Chu CC, Tranel D, Damasio AR, Van Hoesen GW. The autonomic-related cortex: pathology in Alzheimer's disease. Cereb Cortex 7: 86-95 (1997).

[203] Marshall GA, Fairbanks LA, Tekin S, Vinters HV, Cummings JL. Neuropathological correlates of apathy in Alzheimer's disease. Dement Geriatr Cogn Disord 21: 144-7 (2006).
[204] Mintun MA, Larossa GN, Sheline YI, Dence CS, Lee SY, Mach RH, et al. [11C]PIB in a nondemented population: potential antecedent marker of Alzheimer disease. Neurology 67: 446-52 (2006).

[205] Tekin S, Mega MS, Masterman DM, Chow T, Garakian J, Vinters $\mathrm{HV}$, et al. Orbitofrontal and anterior cingulate cortex neurofibrillary tangle burden is associated with agitation in Alzheimer disease. Ann Neurol 49: 355-61 (2001).

[206] Bruen PD, McGeown WJ, Shanks MF, Venneri A. Neuroanatomical correlates of neuropsychiatric symptoms in Alzheimer's disease. Brain 131: 2455-63 (2008).

[207] Tunnard C, Whitehead D, Hurt C, Wahlund LO, Mecocci P, Tsolaki M, et al. Apathy and cortical atrophy in Alzheimer's disease. Int J Geriatr Psychiatry 26: 741-8 (2011).

[208] Craig AH, Cummings JL, Fairbanks L, Itti L, Miller B, Li J, et al. Cerebral blood flow correlates of apathy in Alzheimer disease. Arch Neurol 53: 1116-20 (1996).

[209] Migneco O, Benoît M, Koulibaly PM, Dygai I, Bertogliati C, Desvignes $\mathrm{P}$, et al. Perfusion brain SPECT and statistical parametric mapping analysis indicate that apathy is a cingulate syndrome: a study in Alzheimer's disease and nondemented patients. NeuroImage 13: 896-902 (2001).

[210] Benoit M, Koulibaly PM, Migneco O, Darcourt J, Pringuey DJ, Robert PH. Brain perfusion in Alzheimer's disease with and without apathy: a SPECT study with statistical parametric mapping analysis. Psychiatr Res 114: 103-11 (2002).

[211] Mitchell RA, Herrmann N, Lanctot KL. The role of dopamine in symptoms and treatment of apathy in Alzheimer's disease. CNS Neurosci Therap 17: 411-27 (2011).

[212] Martorana A, Koch G. "Is dopamine involved in Alzheimer's disease?" Front Aging Neurosci 25: 252 (2014).

[213] Storga D, Vrecko K, Birkmayer JGD, Reibnegger G. Monoaminergic neurotransmitters, their precursors and metabolites in brains of Alzheimer patients. Neurosci Lett 203: 29-32 (1996).

[214] Arai H, Kosaka K, Iiziku R. Changes of biogenic amines and their metabolites in postmortem brains from patients with Alzheimertype dementia. J Neurochem 43: 388-93 (1984).

[215] Nazarali AJ, Reynolds GP. Monoamine neurotransmitters and their metabolites in brain regions in Alzheimer's disease: A postmortem study. Cell Mol Neurobiol 12: 581-7 (1992).

[216] Cross AJ, Crow TJ, Ferrier IN, Johnson JA, Markakis D. Striatal dopamine receptors in Alzheimer-type dementia. Neurosci Lett 52: 1-6 (1984)

[217] De Keyser J, Ebinger G, Vauquelin G. D1-dopamine receptor abnormality in frontal cortex points to a functional alteration of cortical cell membranes in Alzheimer's disease. Arch Neurol 47: 761-3 (1990).

[218] Sweet RA, Hamilton RL, Healy MT, Wisniewski SR, Henteleff R, Pollock BG, et al. Alterations of striatal dopamine receptor binding in Alzheimer disease are associated with Lewy body pathology and antemortem psychosis. Arch Neurol 58: 466-72 (2001).

[219] Pinto T, Lanctôt KL, Herrmann N. Revisiting the cholinergic hypothesis of behavioral and psychological symptoms in dementia of the Alzheimer's type. Ageing Res Rev 10: 404-12 (2011).

[220] Drijgers RL, Aalten, P, Winogrodzka, A, Verhey, FRJ, Leentjens, AFG. Pharmacological treatment of apathy in neurodegenerative diseases: a systematic review. Dement Geriatr Cogn Disord 28: 13$22(2009)$.

[221] Steinberg M, Shao H, Zandi P, Lyketsos CG, Welsh-Bohmer KA, Norton MC, et al. Point and 5-year period prevalence of neuropsychiatric symptoms in dementia: the Cache County Study. Int J Geriatr Psychiatry 23: 170-7 (2008).

[222] Ballard C, Corbett A. Agitation and aggression in people with Alzheimer's disease. Curr Opin Psychiatry 26: 252-9 (2013).

[223] Lavretsky H. Neuropsychiatric symptoms in Alzheimer disease and related disorders: why do treatments work in clinical practice but not in the randomized trials? Am J Geriatr Psychiatry 16: 523-7 (2008).

[224] Matthews KL, Chen CP, Esiri MM, Keene J, Minger SL, Francis PT. Noradrenergic changes, aggressive behavior, and cognition in patients with dementia. Biol Psychiatry 51: 407-16 (2002).

[225] Lai MK, Chen CP, Hope T, Esiri MM. Hippocampal neurofibrillary tangle changes and aggressive behaviour in dementia. Neuroreport 21: 1111-5 (2010).

[226] Hirono N, Mega MS, Dinov ID, Mishkin F, Cummings JL. Left frontotemporal hypoperfusion is associated with aggression in patients with dementia. Arch Neurol 57: 861-6 (2000). 
[227] Lancôt KL, Herrmann N, Nadkarni NK, Leibovitch FS, Caldwell $\mathrm{CB}$, Black SE. Medial temporal hypoperfusion and aggression in Alzheimer's disease. Arch Neurol 61: 1731-7 (2004).

[228] Poulin SP, Dautoff R, Morris JC, Barrett LF, Dickerson BC, for the Alzheimer's Disease Neuroimaging Initiative. Amygdala atrophy is prominent in early Alzheimer's disease and relates to symptom severity. Psychiatr Res 194: 7-13 (2011).

[229] Trzepacz PT, Yu P, Bhamidipati PK, Willis B, Forrester T, Tabas $\mathrm{L}$, et al. Frontolimbic atrophy is associated with agitation and aggression in mild cognitive impairment and Alzheimer's disease. Alzheimers Dement 9: S95-S104 (2013).

[230] Minger SL, Esiri MM, McDonald B, Keene J, Carter J, Hope T, et al. Cholinergic deficits contribute to behavioral disturbance in patients with dementia. Neurology 55: 1460-7 (2000).

[231] Garcia-Alloza M, Gil-Bea FJ, Diez-Ariza M, Chen CP, Francis PT, Lasheras B, et al. Cholinergic-serotonergic imbalance contributes to cognitive and behavioral symptoms in Alzheimer's disease. Neuropsychologia 43: 442-9 (2005).

[232] Herrmann N, Rabheru K, Wang J, Binder C. Galantamine treatment of problematic behavior in Alzheimer disease: post-hoc analysis of pooled data from three large trials. Am J Geriatr Psychiatry 13(6): 527-34 (2005).

[233] Cummings JL, McRae T, Zhang R; for the Donepezil-Sertraline Study Group. Effects of donepezil on neuropsychiatric symptoms in patients with dementia and severe behavioral disorders. Am J Geriatr Psychiatry 14: 605-12 (2006).

[234] Palmer AM, Stratmann GC, Procter AW, Bowen DM. Possible neurotransmitter basis of behavioral changes in Alzheimer's disease. Ann Neurol 23: 616-20 (1988).

[235] Lanctôt KL, Herrmann N, Eryavec G, van Reekum R, Reed K, Naranjo CA. Central serotonergic activity is related to the aggressive behaviors of Alzheimer's disease. Neuropsychopharmacology 27: 646-54 (2002)

[236] Ueki A, Ueno H, Sato N, Shinjo H, Morita Y. Serotonin transporter gene polymorphism and BPSD in mild Alzheimer's disease. J Alzheimers Dis 12: 245-53 (2007).

[237] Sweet RA, Pollock BG, Sukonick DL, Mulsant BH, Rosen J, Klunk WE, et al. The 5-HTTPR polymorphism confers liability to a combined phenotype of psychotic and aggressive behavior in Alzheimer disease. Int Psychogeriatr 13: $401-409$ (2001)

[238] Russo-Neustadt A, Zomorodian TJ, Cotman CW. Preserved cerebellar tyrosine hydroxylase-immunoreactive neuronal fibers in a behaviorally aggressive subgroup of Alzheimer's disease patients. Neuroscience 87: 55-61 (1998)

[239] Snaith RP, Zigmond AS. The hospital anxiety and depression scale. Br Med J (Clin Res Ed) 292: 344 (1986).

[240] Lyketsos CG, Steinberg M, Tschanz JT, Norton MC, Steffens DC, Breitner JC. Mental and behavioral disturbances in dementia: findings from the Cache County Study on Memory in Aging. Am J Psychiatry 157: 708-14 (2000).

[241] Engelborghs S, Maertens K, Nagels G, Vloeberghs E, Mariën P, Symons A, et al. Neuropsychiatric symptoms of dementia: crosssectional analysis from a prospective, longitudinal Belgian study. Int J Geriatr Psychiatry 20: 1028-37 (2005).

[242] Hashimoto H, Monserratt L, Nguyen P, Feil D, Harwood D, Mandelkern MA, et al. Anxiety and regional cortical glucose metabolism in patients with Alzheimer's disease. J Neuropsychiatr Clin Neurosci 18: 521-8 (2006).

[243] Beauquis J, Vinuesa A, Pomilio C, Pavía P, Galván V, Saravia F. Neuronal and glial alterations, increased anxiety, and cognitive impairment before hippocampal amyloid deposition in PDAPP mice, model of Alzheimer's disease. Hippocampus 24: 257-69 (2014).

[244] Jeste DV, Finkel SI. Psychosis of alzheimer's disease and related dementias. diagnostic criteria for a distinct syndrome. Am J Geriatr Psychiatry 8: 29-34 (2000).

[245] Förstl H, Besthorn C, Burns A, Geiger-Kabisch C, Levy R, Sattel A. Delusional misidentification in Alzheimer's disease: a summary of clinical and biological aspects. Psychopathology 27: 194-9 (1994).

[246] Farber NB, Rubin EH, Newcomer JW, Kinscherf DA, Miller JP, Morris JC, et al. Increased neocortical neurofibrillary tangle density in subjects with Alzheimer disease and psychosis. Arch Gen Psychiatry 57: 1165-73 (2000).

[247] Ballard CG, Jacoby R, Del Ser T, Khan MN, Munoz DG, Holmes $\mathrm{C}$, et al. Neuropathological substrates of psychiatric symptoms in prospectively studied patients with autopsy-confirmed dementia with lewy bodies. Am J Psychiatry 161: 843-9 (2004).

[248] McShane R, Gedling K, Reading M, McDonald B, Esiri MM, Hope T. Prospective study of relations between cortical Lewy bodies, poor eyesight, and hallucinations in Alzheimer's disease. J Neurol Neurosurg Psychiatry 59: 185-8 (1995).

[249] Holroyd S, Shepherd ML, Downs JH $3^{\text {rd }}$. Occipital atrophy is associated with visual hallucinations in Alzheimer's disease. J Neuropsychiatr Clin Neurosci 12: 25-8 (2000).

[250] Lin SH, Yu CY, Pai MC. The occipital white matter lesions in Alzheimer's disease patients with visual hallucinations. Clin Imaging 30: 388-93 (2006).

[251] Serra L, Perri R, Cercignani M, Spanò B, Fadda L, Marra C, et al. Are the behavioral symptoms of Alzheimer's disease directly associated with neurodegeneration? J Alzheimers Dis 21: 627-39 (2010).

[252] Förstl H, Burns A, Levy R, Cairns N. Neuropathological correlates of psychotic phenomena in confirmed Alzheimer's disease. $\mathrm{Br} \mathrm{J}$ Psychiatry 165: 53-9 (1994)

[253] Lee DY, Choo IH, Kim KW, Jhoo JH, Youn JC, Lee UY, et al. vWhite matter changes associated with psychotic symptoms in Alzheimer's disease patients. J Neuropsychiatr Clin Neurosci 18: 191-8 (2006).

[254] Zubenko GS, Moossy J, Martinez AJ, Rao G, Claassen D, Rosen J, Kopp U. Neuropathologic and neurochemical correlates of psychosis in primary dementia. Arch Neurol 48: 619-24 (1991).

[255] Lai MK, Lai OF, Keene J, Esiri MM, Francis PT, Hope T, et al. Psychosis of Alzheimer's disease is associated with elevated muscarinic M2 binding in the cortex. Neurology 57: 805-11 (2001).

[256] Edwards K, Koumaras , B, Chen M, Gunay, I, Mirski, D. Longterm effects of rivastigmine treatment on the need for psychotropic medications in nursing home patients with Alzheimer's disease: results of a 52-week open-label study. Clin Drug Invest 2: 507-15 (2005).

[257] Vermeiren Y, Van Dam D, Aerts T, Engelborghs S, Martin JJ, De Deyn PP. The monoaminergic footprint of depression and psychosis in dementia with Lewy bodies compared to Alzheimer's disease. Alzheimers Res Ther 7: 7 (2015).

[258] Mega MS, Lee L, Dinov ID, Mishkin F, Toga AW, Cummings JL. Cerebral correlates of psychotic symptoms in Alzheimer's disease. J Neurol Neurosurg Psychiatry 69: 167-71 (2000).

[259] Staff RT, Shanks MF, Macintosh L, Pestell SJ, Gemmell HG, Venneri A. Delusions in Alzheimer's disease: SPET evidence of right hemispheric dysfunction. Cortex 35: 549-60 (1999).

[260] Geroldi C, Bresciani L, Zanetti O, Frisoni GB. Regional brain atrophy in patients with mild Alzheimer's disease and delusions. Int Psychogeriatr 14: 365-78 (2002).

[261] Mentis MJ, Weinstein EA, Horwitz B, McIntosh AR, Pietrini P, Alexander GE, et al. Abnormal brain glucose metabolism in the delusional misidentification syndromes: a positron emission tomography study in Alzheimer disease. Biol Psychiatry 38: 438-49 (1995).

[262] Lopez OL, Becker JT, Brenner RP, Rosen J, Bajulaiye OI, Reynolds CF 3rd. Alzheimer's disease with delusions and hallucinations: neuropsychological and electroencephalographic correlates. Neurology 41: 906-12 (1991).

[263] Edwards-Lee T, Cook I, Fairbanks L, Leuchter A, Cummings JL. Quantitative electroencephalographic correlates of psychosis in Alzheimer disease. Neuropsychiatry Neuropsychol Behav Neurol 13: $163-70$ (2000)

[264] Hofman MA, Swaab DF. Living by the clock: The circadian pacemaker in older people. Ageing Res Rev 5: 33-51 (2006).

[265] Coogan AN, Schutová B, Husung S, Furczyk K, Baune BT, Kropp $\mathrm{P}$, et al. The circadian system in Alzheimer's disease: disturbances, mechanisms, and opportunities. Biol Psychiatry 74: 333-9 (2013).

[266] Bachman D, Rabins P. "Sundowning" and other temporally associated agitation states in dementia patients. Annu Rev Med 57: 499511 (2006).

[267] Benca R, Duncan MJ, Frank E, McClung C, Nelson RJ, Vicentic A. Biological rhythms, higher brain function, and behavior: Gaps, opportunities, and challenges. Brain Res Rev 62: 57-70 (2009).

[268] Swaab DF, Fliers E, Partiman TS. The suprachiasmatic nucleus of the human brain in relation to sex, age and senile dementia. Brain Res 342: 37-44 (1985).

[269] Stopa EG, L Volicer, V Kuo-Leblanc, D Harper, D Lathi, B Tate, et al. Pathologic evaluation of the human suprachiasmatic nucleus in severe dementia J Neuropathol Exp Neurol 58: 29-39 (1999). 
[270] Ju YE, McLeland JS, Toedebusch CD, Xiong C, Fagan AM, Duntley SP, et al. Sleep quality and preclinical Alzheimer disease. JAMA Neurol 70: 587-93 (2013).

[271] Mander BA, Marks SM, Vogel JW, Rao V, Lu B, Saletin JM, et al. $\beta$-amyloid disrupts human NREM slow waves and related hippocampus-dependent memory consolidation. Nat Neurosci 18: 10511057 (2015).

[272] Vanecek J, Watanabe K. Mechanisms of melatonin action in the pituitary and SCN. Adv Exp Med Biol 460: 191-8 (1999).

[273] Pappolla MA, Chyan YJ, Poeggeler B, Frangione B, Wilson G, Ghiso $\mathrm{J}$, et al. An assessment of the antioxidant and the antiamyloidogenic properties of melatonin: implications for Alzheimer's disease. J Neural Transm 107: 203-31 (2000).

[274] Zhou JN, Liu RY, Kamphorst W, Hofman MA, Swaab DF. Early neuropathological Alzheimer's changes in aged individuals are accompanied by decreased cerebrospinal fluid melatonin levels. J Pineal Res 35: 125-30 (2003).

[275] Wu YH, Feenstra MG, Zhou JN, Liu RY, Toranõ JS, Van Kan HJ, et al. Molecular changes underlying reduced pineal melatonin levels in Alzheimer disease: alterations in preclinical and clinical stages. J Clin Endocrinol Metab 88: 5898-906 (2003).
[276] Wisor JP, DM Edgar, J Yesavage, HS Ryan, CM McCormick, N Lapustea, et al. Sleep and circadian abnormalities in a transgenic mouse model of Alzheimer's disease: A role for cholinergic transmission. Neuroscience 131: 375-85 (2005).

[277] Fuh JL, Wang SJ, Cummings JL. Neuropsychiatric profiles in patients with Alzheimer's disease and vascular dementia. J Neurol Neurosurg Psychiatry 76: 1337-41 (2005).

[278] Del Ser T, Hachinski V, Merskey H, Munoz DG. Alzheimer's disease with and without cerebral infarcts. J Neurol Sci 231: 3-11 (2005)

[279] Berlow YA, Wells WM, Ellison JM, Sung YH, Renshaw PF, Harper DG. Neuropsychiatric correlates of white matter hyperintensities in Alzheimer's disease. Int J Geriatr Psychiatry 25: 780-8 (2010).

[280] Boeve BF, Silber MH, Parisi JE, Dickson DW, Ferman TJ, Benarroch EE, et al. Synucleinopathy pathology and REM sleep behavior disorder plus dementia or parkinsonism. Neurology 61: 40-5 (2003) 